\title{
CAMA
}

Centre for Applied Macroeconomic Analysis

\section{Private News and Monetary Policy - Forward Guidance as Bayesian Persuasion}

\section{CAMA Working Paper 91/2019 December 2019}

\section{Ippei Fujiwara}

Faculty of Economics, Keio University

Crawford School of Public Policy, ANU

Centre for Applied Macroeconomic Analysis, ANU

\section{Yuichiro Waki}

Department of Economics, Aoyama Gakuin University

\section{Abstract}

When the central bank has information that can help the private sector predict the future better, should it communicate such information to the public? In a simple New Keynesian model, such Delphic forward guidance unambiguously reduces ex ante welfare by increasing the variability of inflation and the output gap. In other words, it cannot persuade private agents to change their actions in favor of the central bank. In more elaborate DSGE models, the welfare effect may be either positive or negative, depending on the type of shock as well as distortions and frictions. These results suggest that improving welfare by Delphic forward guidance may be particularly difficult under model uncertainty. 


\section{Keywords}

news shock, optimal monetary policy, private information, Bayesian persuasion, forward guidance, New Keynesian models

\section{JEL Classification}

E30, E40, E50

\section{Address for correspondence:}

(E) cama.admin@anu.edu.au

\section{ISSN 2206-0332}

The Centre for Applied Macroeconomic Analysis in the Crawford School of Public Policy has been established to build strong links between professional macroeconomists. It provides a forum for quality macroeconomic research and discussion of policy issues between academia, government and the private sector.

The Crawford School of Public Policy is the Australian National University's public policy school, serving and influencing Australia, Asia and the Pacific through advanced policy research, graduate and executive education, and policy impact. 


\title{
Private News and Monetary Policy
}

\author{
Forward Guidance as Bayesian Persuasion ${ }^{*}$
}

\author{
Ippei Fujiwara $^{\dagger}$ \\ Keio / ANU / ABFER / CAMA
}

\author{
Yuichiro Waki ${ }^{\ddagger}$ \\ Aoyama Gakuin / Queensland
}

\begin{abstract}
When the central bank has information that can help the private sector predict the future better, should it communicate such information to the public? In a simple New Keynesian model, such Delphic forward guidance unambiguously reduces ex ante welfare by increasing the variability of inflation and the output gap. In other words, it cannot persuade private agents to change their actions in favor of the central bank. In more elaborate DSGE models, the welfare effect may be either positive or negative, depending on the type of shock as well as distortions and frictions. These results suggest that improving welfare by Delphic forward guidance may be particularly difficult under model uncertainty.
\end{abstract}

\section{JEL Classification: E30; E40; E50 \\ Keywords: $\quad$ news shock; optimal monetary policy; private information; Bayesian persuasion; forward guidance; New Keynesian models}

\footnotetext{
*We have benefited from discussions with David Aikman, Kosuke Aoki, Gadi Barlevy, Robert Barsky, Marco Bassetto, Paul Beaudry, Jim Bullard, Larry Christiano, Francois Gourio, Luigi Iovino, Leonard Melosi, Tomasso Monacelli, Ed Nelson, Oreste Tristani, Kazuo Ueda, Jacob Wong, Michael Woodford, and the seminar and conference participants at Kyoto University, University of Sydney, University of Melbourne, University of Adelaide, the DSGE workshop, Keio University, University of Tokyo, Hitotsubashi University, European Central Bank, the Reserve Bank of Australia Quantitative Macroeconomics Workshop 2015, the Second Annual CIGS End of Year Macroeconomics Conference, RIETI, Bank of England, Bocconi University, Bank of Japan, the Workshop of Australasian Macroeconomics Society 2017, and FRB Chicago. We also thank Tamon Takamura for sharing the replication code with us. This study is conducted as a part of the project "On Monetary and Fiscal Policy under Structural Changes and Societal Aging" undertaken at the Research Institute of Economy, Trade and Industry (RIETI). We are also grateful for financial support from JSPS KAKENHI Grant-in-Aid for Scientific Research (A) Grant Number 15H01939 and 18H036038.

${ }^{\dagger}$ Faculty of Economics, Keio University, Tokyo, Japan. Crawford School of Public Policy, Australian National University, Canberra, Australia. Email: ippei.fujiwara@keio.jp

‡Department of Economics, Aoyama Gakuin University, Tokyo, Japan. Email: ywakiecon@gmail.com
} 


\section{Introduction}

Central banks have been thought to possess private information about future economic conditions. Romer and Romer (2000) provide empirical evidence of asymmetric information between the central bank and private agents: "the Federal Reserve has considerable information about inflation beyond what is known to commercial forecasters. ${ }^{1 "}$ The possession of such superior information by the central bank raises several questions. How should monetary policy be designed when the central bank has private information about future economic conditions? Does the central bank benefit from managing the private sector's expectations by utilizing such information?

This paper investigates whether central banks should reveal private news, either by communicating it or by undertaking observable policy actions, in representativeagent dynamic stochastic general equilibrium (DSGE) models with nominal rigidities, by adding news about future economic conditions. DSGE models with nominal rigidities are best suited for our analysis because the central bank in the models can manage the expectations of forward-looking agents by conveying its private news. In addition, these models are widely used in central banks to guide policies.

Central banks' communication of their private news is of practical relevance. Campbell, Evans, Fisher, and Justiniano (2012) distinguish between Delphic forward guidance, which involves public statements about "a forecast of macroeconomic performance and likely or intended monetary policy actions based on the policymaker's potentially superior information about future macroeconomic fundamentals and its own policy goals", and Odyssean forward guidance that involves the policy-maker's commitment to a future, possibly state-contingent, action plan. They found empirical evidence suggesting that the forward guidance employed by the FOMC has "a substantial Delphic component". Although the importance of Odyssean forward guidance has been well established in the New Keynesian monetary policy literature, it is not yet known whether Delphic forward guidance is useful in New Keynesian models and this paper sheds light on this issue.

The present paper argues that improving social welfare through Delphic forward

\footnotetext{
${ }^{1}$ Fujiwara (2005) shows that central bank forecasts significantly affect those by professional forecasters.
} 
guidance is indeed difficult, if not impossible, in these DSGE models. Our argument is based on a theoretical result in simple New Keynesian models and on numerical experiments in more elaborate models.

By extending a textbook New Keynesian model (Woodford, 2003) to incorporate a direct communication channel from the central bank, we show that Delphic forward guidance unambiguously decreases ex ante welfare. The benevolent central bank finds it optimal to commit to not revealing its superior information about future shocks, either directly through communication or indirectly through observable policy actions. The result holds for any shocks - a natural rate shock, a cost-push shock, and a shock to the welfare loss function - and even in the presence of an effective lower bound on the nominal interest rate.

The underlying mechanism is simple and operates through the forward-looking New Keynesian Phillips curve. Consider a simple New Keynesian model in which the central bank has preferences for stabilizing inflation and the output gap. When the private sector becomes better informed about future shocks, its inflation expectations vary with them and, from the ex ante point of view, become more volatile. This increased volatility of inflation expectations acts as an additional source of disturbance in the New Keynesian Phillips curve, translates into higher variability of inflation and the output gap, and is therefore harmful to the central bank that aims to stabilize these variables.

Our results are closely related to the literature of Bayesian persuasion $a$ la Rayo and Segal (2010), Kamenica and Gentzkow (2011) and Jehiel (2015). The settings in this model can be easily mapped into that of Bayesian persuasion: the central bank is the informed party (Sender) that designs and commits to information disclosure policy, i.e., forward guidance, to maximize its ex ante expected payoff, and the private agents constitute the uninformed party (Receiver) that takes action based on its posterior belief. The central bank cannot persuade private agents to take action in favor of its objective function through Delphic forward guidance.

Committing to secrecy is optimal ex ante but may not be so ex post, implying there is a time-inconsistency problem. Imagine that the economy is hit by a positive costpush shock that incentivizes sellers to set high prices with everything else being equal. Once the central bank observes a signal that a negative cost-push shock will likely hit 
in the future, it is tempted to convey that information to the private sector because it reduces the sellers' inflation expectations and discourages them from setting high prices. Time-inconsistency of commitment policy is well known in New Keynesian models, but our result is new in that it shows the possibility of time-inconsistency problem in the communication policy too.

We complement the theoretical result in the relatively simple model with numerical results in a more elaborate, nonlinear DSGE model that is based on Christiano, Eichenbaum, and Evans (2005) and Smets and Wouters (2003, 2007). It features multiple distortions, frictions and shocks. Both price and wage are sticky and are subject to markup shocks and to backward indexation. The household accumulates capital subject to investment adjustment costs, implying that there is a channel through which better information about future technology shocks improves welfare through better investment decisions. The monetary policy follows the Taylor rule with inertia and a monetary policy shock. We solve the model using the second-order approximation, assuming that Delphic forward guidance perfectly reveals any of the four shocks $n$ periods in advance.

In the full-blown DSGE model, Delphic forward guidance can improve welfare, but the central bank has to be selective of which shocks to reveal as the sign of the welfare effect depends on the shock type. Compared to the no-forward-guidance case $(n=0)$, forward guidance improves welfare if it is about price markup and monetary policy shocks, but it reduces welfare for wage markup and technology shocks. Furthermore, the central bank generally needs to know how much the private sector knows without forward guidance in order to use its information to improve welfare. This is because the welfare effect is not monotone in $n$ in general. If the private sector can, without forward guidance, observe the two-period ahead price markup shock, then providing information about the same shock in further distant future reduces welfare, implying that being secretive about the price markup shock is desirable. ${ }^{2}$

However, choosing which shocks and how much information to reveal is indeed difficult under model uncertainty. The welfare effects of Delphic forward guidance are determined by a rather complicated interaction between distortions and frictions

\footnotetext{
${ }^{2}$ Similarly, the welfare effect of forward guidance about the technology and the wage markup shocks is positive if the private sector observes these shocks two periods in advance already.
} 
in the model, and their sign can change quite easily when some distortions and frictions are included or excluded from the model. Overall, our results suggest that it is difficult to use Delphic forward guidance as a tool to improve welfare in representativeagent DSGE models. For example, with weaker wage rigidity, forward guidance about the price markup shock reduces welfare, as we have found in the simple New Keynesian model; without nominal rigidities, forward guidance about the technology shock improves welfare; without policy inertia, forward guidance about the monetary policy shock reduces welfare, etc. These implications are opposite to what we find in the full-blown model. In contrast, forward guidance about the wage markup shock consistently generates non-positive welfare effects even when we remove distortions and frictions in the model.

The importance of managing expectations has been emphasized in the New Keynesian literature (Woodford, 2003). ${ }^{3}$ Our results overall suggest that, in the same class of models, it is difficult to improve welfare using Delphic forward guidance based on private news. The central bank should instead aim to conduct Odyssean forward guidance by communicating its state-contingent policy, i.e., what it will do in response to these shocks after they materialize.

This paper is structured as follows. Section 2 provides the baseline setting and the main theorem about the undesirability of information revelation and discusses some extensions. In Section 3 we conduct numerical analysis. Section 4 concludes.

\subsection{Related literature}

Our paper is most closely related to the literature of Bayesian persuasion (Rayo and Segal, 2010; Kamenica and Gentzkow, 2011; Jehiel, 2015). As in the literature, we assume that an informed party (the central bank) can commit to a signal-generating structure before observing private information and characterize the optimal disclosure policy from the viewpoint of the informed party. Therefore, this paper can be

\footnotetext{
${ }^{3}$ Its importance has been also emphasized in real-world policy-making after many central banks in advanced economies reduced short-term nominal interest rates to the lowest possible level in response to the recent financial crisis. Forward guidance is not necessarily a policy prescription under liquidity trap. Svensson (2014) states that "for many years, some central banks have used forward guidance as a natural part of their normal monetary policy." Its usefulness has been reported even in normal time.
} 
framed as a macroeconomic application of Bayesian persuasion. A distinct feature of our model is that the informed party also takes action that directly affects the private agents' incentives and that, if the action utilizes private information, may indirectly reveal some private information. In an accompanying paper (Fujiwara and Waki, forthcoming) we analyze the welfare effect of Delphic forward guidance in the context of fiscal policy.

To focus on private news, we assume that contemporaneous shocks are perfectly observed by private agents. We also assume symmetric information among private agents in order to focus on information asymmetry between the central bank and the private sector. There has been a vast number of studies that focus on the role of the central bank's disclosure policy in coordinating the actions of private agents who are heterogeneously informed about contemporaneous economic conditions: for example, Morris and Shin (2002) and Angeletos and Pavan (2007). The works related to our paper in this literature are Hellwig (2005) and Lorenzoni (2010). In both papers, monopolistically competitive sellers are heterogeneously informed about the contemporaneous shock and set their nominal prices under some information constraints. In Hellwig (2005), the heterogenous information is about money supply shocks and public information unambiguously improves welfare by lowering belief dispersion and price dispersion among sellers. In Lorenzoni (2010), the heterogenous information is about aggregate productivity, and a more precise public signal is shown to improve social welfare when the monetary policy rule is chosen optimally. If we were to introduce heterogeneously informed sellers to our model, then the optimal communication policy would strike a balance between the gain from coordination and the loss from volatility. ${ }^{4}$ In this literature, it is also found that increased precision of a public signal can reduce welfare, but the reason is the coordination motives. Our paper shows that information revelation can be detrimental to welfare even without heterogeneous information or the coordination motives. ${ }^{5}$

\footnotetext{
${ }^{4}$ There are other papers that investigate the role of central bank's information revelation when private agents are heterogeneously informed: e.g., Gaballo (2016) and Walsh (2007). Melosi (2017) develops a New Keynesian model with dispersed information to examine the role of monetary policy to convey the central bank's private information about the current shocks. In contrast to our paper, his analysis is a positive one and demonstrates that the dispersed information model outperforms the homogeneous information model.

${ }^{5}$ Svensson (2006) argues that the welfare-reducing property of increased precision of the public
} 
In our paper the central bank is assumed to be able to commit to a signal-generating structure as in the literature of Bayesian persuasion, and there is no strategic interaction between the central bank and the private agents. By contrast, Stein (1989) and Moscarini (2007) analyze strategic information transmission by setting up a cheap-talk game (Crawford and Sobel, 1982). They show that, although full information revelation is desirable, only imperfect communication is possible in equilibrium, thereby providing a theory of imprecise announcement from policy-makers. Moscarini (2007) further shows that the more precise signal the central bank observes, the more information is revealed and the higher is the level of welfare. The reason that information disclosure is desirable is that the central bank in their model has private information about shocks to its current policy objective but not about news shocks. A recent paper by Bassetto (forthcoming) analyzes the role of forward guidance in a dynamic cheaptalk game. His model is not a New Keynesian model and the central bank's private information is not about future shocks.

This paper is also related to the literature of news shocks, including Beaudry and Portier (2006, 2014), Jaimovich and Rebelo (2009), Fujiwara, Hirose, and Shintani (2011) and Schmitt-Grohé and Uribe (2012). These papers give positive analysis and largely focus on the role of news about future technology shocks in accounting for business cycle fluctuations and assume symmetric information between the central bank and the private sector. We depart from symmetric information to examine how the central bank should communicate superior information and examine the normative aspect of news shocks.

Representative-agent DSGE models are known to exhibit quantitatively too strong responses to a commitment to a policy rate cut at a future date. Del Negro, Giannoni, and Patterson (2012) have called this the "forward guidance puzzle." The puzzle is, however, about the size of the response and not the sign. Recent studies find ways to reduce this responsiveness by using a heterogeneous-agent incomplete market framework (McKay, Nakamura, and Steinsson, 2016) or by introducing bounded rationality (Gabaix, 2016) or both (Farhi and Werning, 2017). McKay, Nakamura, and Steinsson (2017) demonstrate that a representative-agent model can mimic the aggre-

signal is rather limited to a small region of the parameter space in the model of Morris and Shin (2002). In the simple New Keynesian model, the undesirability of information revelation is a global property. 
gate consumption response in their incomplete market model by introducing further "discounting" in the Euler equation. Even with the discounted Euler equation, if the central bank's loss function is a convex function of inflation and the output gap, then the central bank would still find it optimal to commit to secrecy. The welfare loss from transparency would be, however, smaller. ${ }^{6}$

\section{Theoretical results}

Our baseline model is an extension of the simple New Keynesian model in which the monetary policy trade-off is given by distortionary cost-push shocks to the New Keynesian Phillips curve, and the central bank is assumed to be better-informed about future shocks. The central bank may send costless messages to the private sector, or the private sector may infer the central bank's private information from central bank actions that depend on its private information (as in, e.g., Cukierman and Meltzer, 1986). The question we ask is, does the central bank find it beneficial to commit to making the private sector better-informed about future shocks? We find that the answer to this question is no: the optimal commitment policy never reveals or exploits superior information possessed by the central bank. This result holds even when the central bank possesses private news about the policy objective or when there is a zero lower bound constraint on nominal interest rates.

Proofs are simple and based on Jensen's inequality, exploiting the linearity of the New Keynesian Phillips curve and the strict convexity of the loss function. ${ }^{7}$ Therefore, the result of the desirability of secrecy about future fundamental shocks holds true in more general, linearized DSGE models without endogenous state variables. ${ }^{8}$

\footnotetext{
${ }^{6}$ However, once we depart from the representative-agent New Keynesian model, we cannot in general justify such a loss function as a measure of social welfare loss.

${ }^{7}$ Linearity is stronger than we need. A sufficient condition for our result is that the constraint set of the Ramsey problem is convex.

${ }^{8}$ We depart from the linear quadratic framework and also incorporate endogenous state variables in Section 3.3.
} 


\subsection{Environment}

We employ the standard analytical framework for optimal monetary policy as in Woodford (2003), Galí (2008) or Walsh (2010). The framework is extended here to incorporate the central bank's superior information about future shocks and communication about it. A representative household consumes the final good, supplies labor to intermediate firms, and trades state-contingent claims in complete markets. There is a unit measure of intermediate firms, and firm $i \in[0,1]$ supplies the intermediate good $i$ in a monopolistically competitive market. The final good firm produces the final good from intermediate goods, using the Dixit-Stiglitz aggregator. The central bank chooses the nominal interest rate as well as how much information to reveal to the private sector.

All exogenous shocks we describe below are modeled as random variables on the probability space $(\Omega, \mathcal{F}, P)$.

At the beginning of each period $t$, everyone in the economy observes contemporaneous fundamental shocks to the natural rate of interest, $r_{t}^{n} \in \mathbb{R}$, and the cost-push shock, $u_{t} \in \mathbb{R}$, and a common signal about future shocks, $s_{t}^{C O M} \in \mathbb{R}^{N_{C O M} .9}$ Then a private signal about future shocks, $s_{t}^{C B} \in \mathbb{R}^{N_{C B}}$, and a non-fundamental shock, $\epsilon_{t} \in \mathbb{R}^{N_{\epsilon}}$, realize and are privately observed only by the central bank. The signals, $s^{C O M}$ and $s^{C B}$, and the non-fundamental shock $\epsilon$ can be multidimensional, i.e., both $N_{C O M}$ and $N_{C B}$ can be strictly bigger than one. For example, $s_{t}^{C O M}=u_{t+1}$ and $s_{t}^{C B}=\left(u_{t+2}, u_{t+3}, \ldots\right)$. In this case, both the central bank and the private sector observe next period's mark-up shock, but the central bank also observes the whole sequence of mark-up shocks. The non-fundamental shock is assumed to be independent of the fundamental shocks and can be also multidimensional: $N_{\epsilon} \geq 1$. The central bank may use the non-fundamental shock to add random noise to the message it sends to the private sector.

We denote a vector of exogenous random variables which the central bank ob-

\footnotetext{
${ }^{9}$ Strictly speaking, the natural rate is usually a linear combination of the productivity and the government spending shocks in a current period and the conditional expectations of these shocks in the next period. The central bank's communication policy can influence the contemporaneous natural rate by providing more information about the next period shocks. Because our theoretical results remain true even if we take it into account, we assume that $r_{t}^{n}$ is unaffected by communication for notational simplicity.
} 
serves at the beginning of period $t$ by $h_{t}$, i.e., $h_{t}=\left(r_{t}^{n}, u_{t}, s_{t}^{C O M}, s_{t}^{C B}, \epsilon_{t}\right)$. The central bank's information is represented by a filtration $\mathcal{G}^{C B}=\left\{\mathcal{G}_{t}^{C B}\right\}_{t=0}^{\infty}$, where for each $t$, $\mathcal{G}_{t}^{C B} \subset \mathcal{F}$ is the smallest $\sigma$-field for which a sequence $h^{t}:=\left(h_{0}, h_{1}, \ldots, h_{t}\right)$ is measurable.

After observing $h_{t}$, the central bank chooses the nominal interest rate, $i_{t}$, and a public message, $m_{t}$. Both $i_{t}$ and $m_{t} \in \mathbb{R}^{N_{m}}$ depend only on the information possessed

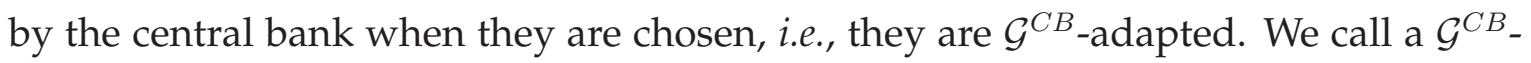
adapted process $\left\{\left(i_{t}, m_{t}\right)\right\}_{t=0}^{\infty}$ the central bank's policy. We assume that $N_{m} \geq N_{C B}$ so that the central bank can always communicate the private signal itself if it wants to.

All private agents observe $\left(i_{t}, m_{t}\right)$ without error. Let $h_{t}^{P}=\left(r_{t}^{n}, u_{t}, s_{t}^{C O M}, i_{t}, m_{t}\right)$ be the private sector's observation in period $t$. The private sector's information is represented by a filtration $\mathcal{G}^{P}=\left\{\mathcal{G}_{t}^{P}\right\}_{t=0}^{\infty}$. The private agents' decisions in period $t$ depend only on the information that is summarized by $\mathcal{G}_{t}^{P}$.

Now we define a rational expectation equilibrium (REE) in this setting. In addition to the standard equilibrium conditions such as the New Keynesian Phillips curve and the Dynamic IS equation, it is required that (i) the private sector's infomation set is determined by the central bank's policy; and (ii) the output gap and inflation in period $t$ must depend only on the private sector's information. Formally, a REE given a $\mathcal{G}^{C B}$-adapted process $\left\{\left(i_{t}, m_{t}\right)\right\}_{t=0}^{\infty}$ is a pair of a filtration $\mathcal{G}^{P}$ and a stochastic process $\left\{\left(\pi_{t}, x_{t}\right)\right\}_{t=0}^{\infty}$ such that: (i) for each $t, \mathcal{G}_{t}^{P}$ is the smallest $\sigma$-field for which a sequence of $h^{P, t}:=\left(h_{0}^{P}, h_{1}^{P}, \ldots, h_{t}^{P}\right)$ is measurable; (ii) $\left\{\left(\pi_{t}, x_{t}\right)\right\}_{t=0}^{\infty}$ is $\mathcal{G}^{P}$-adapted; and (iii) the New Keynesian Phillips curve:

$$
\pi_{t}=\kappa x_{t}+\beta \mathbb{E}\left[\pi_{t+1} \mid \mathcal{G}_{t}^{P}\right]+u_{t},
$$

and the Dynamic IS equation:

$$
x_{t}=\mathbb{E}\left[x_{t+1} \mid \mathcal{G}_{t}^{P}\right]-\sigma^{-1}\left\{i_{t}-\mathbb{E}\left[\pi_{t+1} \mid \mathcal{G}_{t}^{P}\right]-r_{t}^{n}\right\},
$$

are satisfied. Here, $\kappa$ is the standard slope parameter for the Phillips curve, $\beta$ is the representative household's preference discount factor, and $\sigma$ is the inverse of the intertemporal elasticity of substitution. 
The central bank's ex ante loss function is given by

$$
\mathbb{E}\left[\sum_{t=0}^{\infty} \delta^{t} L\left(\pi_{t}, x_{t}\right)\right]
$$

where $L$ is a strictly convex, momentary loss function and $\delta \in(0,1)$ is the discount factor. This loss function represents the idea that the central bank pursues some kind of "dual mandate" - the central bank benefits from stabilizing inflation and the output gap. This specification nests the standard linear-quadratic model with a benevolent central bank minimizing the loss function which is obtained from the second-order approximation of the representative household's utility in a Calvo-type sticky-price model:

$$
\mathbb{E}\left[\sum_{t=0}^{\infty} \beta^{t} \frac{1}{2}\left(\pi_{t}^{2}+\frac{\kappa}{\epsilon} x_{t}^{2}\right)+\text { t.i.p. }\right],
$$

where $\epsilon$ denotes the CES parameter for intermediate goods and t.i.p. refers to the terms independent of policy. ${ }^{10}$ Online Appendix A.1 shows that the above standard quadratic loss funcion is valid in the present setting with communication.

Note that the expectation in (3) is the unconditional one and thus the loss is evaluated before any shocks realize and before either the private sector or the central bank receives any information at time 0 . In standard symmetric information cases, it is more common to use the expectation conditional on time- 0 information, i.e., after the time-0 shocks have realized. All our theoretical results hold even if we replace the unconditional expectation with the conditional one given $\left(r_{0}^{n}, u_{0}, s_{0}^{C O M}\right)$. Such a specification is justified under the assumption that the central bank evaluates its loss after the private sector and the central bank receive the common time- 0 information but before the central bank receives any private news.

\footnotetext{
${ }^{10}$ This approximation obtains when the steady-state distortion associated with monopolistic competition is offset by a tax or subsidy, with $x$ denoting the welfare relevant output gap. Approximation is realization-by-realization and never uses equations that involve conditional expectations. See, e.g., Woodford (2003). Therefore, t.i.p. does not include terms affected by information, e.g., forecast errors by the private sector.
} 


\subsection{Desirability of committing to secrecy: an illustrative example}

We first use a simplified model to illustrate that the central bank finds it optimal to commit to being secretive about private news.

Consider a quadratic loss function $\mathbb{E}\left[\sum_{t=0}^{\infty} \beta^{t}\left(\pi_{t}^{2}+b x_{t}^{2}\right) / 2\right]$, and then let $b \rightarrow \infty$ holding other parameters fixed. This makes it extremely costly to have a non-zero output gap, and, in the limit, the loss-minimizing central bank must conduct policy so that the output gap is always zero. Given a complete stabilization of the output gap at zero,

$$
\pi_{t}=u_{t}+\beta \mathbb{E}\left[\pi_{t+1} \mid \mathcal{G}_{t}^{P}\right]=u_{t}+\mathbb{E}\left[\sum_{j=1}^{\infty} \beta^{j} u_{t+j} \mid \mathcal{G}_{t}^{P}\right]
$$

must hold in any REE. Therefore, inflation is solely driven by exogenous shocks and the private sector's expectations about future shocks.

Suppose that $\left\{u_{t}\right\}_{t=0}^{\infty}$ is a sequence of i.i.d. shocks with zero mean and a finite variance of $\sigma_{u}^{2}$ and that a common signal is uninformative $\left(s_{t}^{C O M}=\emptyset\right)$. Imagine that the central bank observes $s_{t}^{C B}=\left(u_{t+1}, u_{t+2}, \ldots, u_{t+N}\right)$ in addition to contemporaneous shocks $\left(r_{t}^{n}, u_{t}\right)$.

Now we ask whether and how setting $m_{t}=\left(u_{t+1}, u_{t+2}, \ldots, u_{t+n}\right)$ affects the inflation outcome and ex ante welfare for $n=0,1, \cdots, N$. When $n=0$, we have

$$
\pi_{t}=u_{t} \text { and } \mathbb{E}\left[\pi_{t}^{2}\right]=\sigma_{u}^{2}
$$

For general $n$, we have

$$
\pi_{t}=u_{t}+\beta u_{t+1}+\cdots+\beta^{n} u_{t+n}
$$

and

$$
\mathbb{E}\left[\pi_{t}^{2}\right]=\sigma_{u}^{2}+\beta^{2} \sigma_{u}^{2}+\cdots+\beta^{2 n} \sigma_{u}^{2}=\frac{1-\beta^{2(n+1)}}{1-\beta^{2}} \sigma_{u}^{2}>\sigma_{u}^{2} .
$$

Hence, welfare loss is monotonically increasing in $n$.

Therefore, ex ante welfare loss strictly increases if the private sector becomes able to observe future cost-push shocks perfectly, and the benevolent central bank wants to commit to not sending perfect signals about future shocks.

The mechanism at work is quite simple. Notice that the additional variability of 
inflation above comes from increased volatility of expected, one-period ahead inflation. Future inflation varies with a future shock, and when the private sector becomes better-informed about a future shock, its inflation expectations move with previously unavailable information. Inflation expectations thus become more volatile. The increased volatility of inflation expectations translates into higher variability of inflation through the New Keynesian Phillips curve. As we show in the next section, this mechanism is also at work in our general setting, in which the output gap is a meaningful choice variable of the central bank and the central bank can send imperfect, noisy signals about its private information.

\subsection{Optimal commitment policy is secretive}

Ramsey problem for the central bank is to choose a $\mathcal{G}^{C B}$-adapted process $\left\{\left(i_{t}, m_{t}\right)\right\}_{t=0}^{\infty}$ so that the best REE given that policy achieves the lowest welfare loss. We say that $\left\{\left(i_{t}, m_{t}, \pi_{t}, x_{t}\right)\right\}_{t=0}^{\infty}$ solves the Ramsey problem if $\left(\mathcal{G}^{P},\left\{\left(\pi_{t}, x_{t}\right)\right\}\right)$ is the best REE given policy $\left\{\left(i_{t}, m_{t}\right)\right\}$ and if $\left\{\left(i_{t}, m_{t}\right)\right\}$ minimizes the welfare loss achieved by the best REE given policy.

As a benchmark, let us consider a situation where the central bank commits to secrecy - it neither reveals private information through message nor responds to it by adjusting the nominal interest rate. The private sector's information is then defined by the filtration generated by $\left\{\left(r_{t}^{n}, u_{t}, s_{t}^{C O M}\right)\right\}$, which we denote by $\mathcal{G}^{M I N}$. Define the optimal secretive commitment policy as follows. First, $\left\{\left(\pi_{t}^{S E C}, x_{t}^{S E C}\right)\right\}$ solves

$$
\min _{\left\{\left(\pi_{t}^{\prime}, x_{t}^{\prime}\right)\right\}} \mathbb{E}\left[\sum_{t=0}^{\infty} \beta^{t} L\left(\pi_{t}^{\prime}, x_{t}^{\prime}\right)\right],
$$

subject to the New Keynesian Phillips curve: for all $t$,

$$
\pi_{t}^{\prime}=\kappa x_{t}^{\prime}+\beta \mathbb{E}\left[\pi_{t+1}^{\prime} \mid \mathcal{G}_{t}^{M I N}\right]+u_{t}
$$

and the information constraint: $\left\{\left(\pi_{t}^{\prime}, x_{t}^{\prime}\right)\right\}$ is $\mathcal{G}^{M I N}$-adapted. $\left\{i_{t}^{S E C}\right\}$ is obtained by solving

$$
x_{t}^{S E C}=\mathbb{E}\left[x_{t+1}^{S E C} \mid \mathcal{G}_{t}^{M I N}\right]-\sigma^{-1}\left\{i_{t}^{S E C}-\mathbb{E}\left[\pi_{t+1}^{S E C} \mid \mathcal{G}_{t}^{M I N}\right]-r_{t}^{n}\right\}
$$


We set $\left\{m_{t}^{S E C}\right\}$ so that $m_{t}^{S E C}=\emptyset$ always. We call $\left\{\left(i_{t}^{S E C}, m_{t}^{S E C}, \pi_{t}^{S E C}, x_{t}^{S E C}\right)\right\}$ the optimal secretive commitment policy.

The following proposition shows that the optimal secretive commitment policy is "the" solution to the Ramsey problem.

Proposition 1 The optimal secretive commitment policy is a solution to the Ramsey problem. Any solution to the Ramsey problem equals the optimal secretive commitment policy with probability one.

Proof of Proposition 1. Suppose to the contrary that in a solution to the Ramsey problem $\left\{\left(i_{t}, m_{t}\right)\right\}_{t=0}^{\infty}$ is not $\mathcal{G}^{M I N}$-adapted. Pick any rational expectation equilibrium given such $\left\{\left(i_{t}, m_{t}\right)\right\}_{t=0}^{\infty}$. Then $\mathcal{G}^{P} \neq \mathcal{G}^{M I N}$.

We construct $\left\{\left(\tilde{\pi}_{t}, \tilde{x}_{t}\right)\right\}$ and $\left\{\left(\tilde{i}_{t}, \tilde{m}_{t}\right)\right\}$ such that (i) $\left\{\left(\tilde{i}_{t}, \tilde{m}_{t}\right)\right\}$ is $\mathcal{G}^{M I N}$-adapted, (ii) $\left(\mathcal{G}^{M I N},\left\{\left(\tilde{\pi}_{t}, \tilde{x}_{t}\right)\right\}\right)$ is a REE given $\left\{\left(\tilde{i}_{t}, \tilde{m}_{t}\right)\right\}$, and (iii) $\mathbb{E}\left[\sum_{t=0}^{\infty} \beta^{t} L\left(\pi_{t}, x_{t}\right)\right] \geq \mathbb{E}\left[\sum_{t=0}^{\infty} \beta^{t} L\left(\tilde{\pi}_{t}, \tilde{x}_{t}\right)\right]$.

Let $\tilde{i}_{t}:=\mathbb{E}\left[i_{t} \mid \mathcal{G}_{t}^{M I N}\right], \tilde{m}_{t}:=\mathbb{E}\left[m_{t} \mid \mathcal{G}_{t}^{M I N}\right], \tilde{\pi}_{t}:=\mathbb{E}\left[\pi_{t} \mid \mathcal{G}_{t}^{M I N}\right]$, and $\tilde{x}_{t}:=\mathbb{E}\left[x_{t} \mid \mathcal{G}_{t}^{M I N}\right]$. These are clearly $\mathcal{G}^{M I N}$-adapted.

Observe that

$$
\begin{aligned}
\tilde{\pi}_{t} & =\mathbb{E}\left[\kappa x_{t}+\beta \mathbb{E}\left[\pi_{t+1} \mid \mathcal{G}_{t}^{P}\right]+u_{t} \mid \mathcal{G}_{t}^{M I N}\right], \\
& =\kappa \tilde{x}_{t}+\beta \mathbb{E}\left[\pi_{t+1} \mid \mathcal{G}_{t}^{M I N}\right]+u_{t}, \\
& =\kappa \tilde{x}_{t}+\beta \mathbb{E}\left[\tilde{\pi}_{t+1} \mid \mathcal{G}_{t}^{M I N}\right]+u_{t} .
\end{aligned}
$$

The last equality holds because of the law of iterated expectations:

$$
\mathbb{E}\left[\pi_{t+1} \mid \mathcal{G}_{t}^{M I N}\right]=\mathbb{E}\left[\mathbb{E}\left[\pi_{t+1} \mid \mathcal{G}_{t+1}^{M I N}\right] \mid \mathcal{G}_{t}^{M I N}\right]
$$

By the same token,

$$
\tilde{x}_{t}=\mathbb{E}\left[\tilde{x}_{t+1} \mid \mathcal{G}_{t}^{M I N}\right]-\sigma^{-1}\left\{\tilde{i}_{t}-\mathbb{E}\left[\tilde{\pi}_{t+1} \mid \mathcal{G}_{t}^{M I N}\right]-r_{t}^{n}\right\} .
$$

Hence $\left(\mathcal{G}^{M I N},\left\{\left(\tilde{\pi}_{t}, \tilde{x}_{t}\right)\right\}\right)$ is a REE given $\left\{\left(\tilde{i}_{t}, \tilde{m}_{t}\right)\right\}$. 
Jensen's inequality implies

$$
\mathbb{E}\left[L\left(\pi_{t}, x_{t}\right)\right]=\mathbb{E}\left[\mathbb{E}\left[L\left(\pi_{t}, x_{t}\right) \mid \mathcal{G}_{t}^{M I N}\right]\right] \geq \mathbb{E}\left[L\left(\mathbb{E}\left[\pi_{t} \mid \mathcal{G}_{t}^{M I N}\right], \mathbb{E}\left[x_{t} \mid \mathcal{G}_{t}^{M I N}\right]\right)\right]=\mathbb{E}\left[L\left(\tilde{\pi}_{t}, \tilde{x}_{t}\right)\right]
$$

Equality holds if and only if $\left(\pi_{t}, x_{t}\right)=\left(\tilde{\pi}_{t}, \tilde{x}_{t}\right)$ with probability one.

Therefore we have established

$$
\mathbb{E}\left[\sum_{t=0}^{\infty} \beta^{t} L\left(\pi_{t}, x_{t}\right)\right] \geq \mathbb{E}\left[\sum_{t=0}^{\infty} \beta^{t} L\left(\tilde{\pi}_{t}, \tilde{x}_{t}\right)\right] \geq \mathbb{E}\left[\sum_{t=0}^{\infty} \beta^{t} L\left(\pi_{t}^{S E C}, x_{t}^{S E C}\right)\right]
$$

For $\left\{\left(i_{t}, m_{t}, \pi_{t}, x_{t}\right)\right\}$ to be a solution to the Ramsey problem,

$$
\left\{\left(\pi_{t}, x_{t}\right)\right\}=\left\{\left(\tilde{\pi}_{t}, \tilde{x}_{t}\right)\right\}=\left\{\left(\pi_{t}^{S E C}, x_{t}^{S E C}\right)\right\}
$$

must hold with probability one.

Because this proposition implies that making the private sector better informed is welfare-reducing, it is also undesirable when the common signal, $s_{t}^{C O M}$, becomes more informative:

Corollary 1 Ex ante welfare loss increases when the common signal, $\left\{s_{t}^{C O M}\right\}$, becomes more informative about future shocks.

\subsubsection{Intuition}

To obtain some intuition, let us rewrite (1) as

$$
\pi_{t}-\kappa x_{t}=\underbrace{\left\{\beta \mathbb{E}\left[\pi_{t+1} \mid \mathcal{G}_{t}^{M I N}\right]+u_{t}\right\}}_{\text {"original" term }}+\underbrace{\beta\left\{\mathbb{E}\left[\pi_{t+1} \mid \mathcal{G}_{t}^{P}\right]-\mathbb{E}\left[\pi_{t+1} \mid \mathcal{G}_{t}^{M I N}\right]\right\}}_{\text {"updating" term }} .
$$

Observe that the central bank that minimizes (3) benefits from stabilizing the righthand side, because it can then stabilize inflation and the output gap. The right-hand side consists of two terms, the "original" term and the "updating" term. The former collects the terms that are present even when the private sector's information is given by $\mathcal{G}_{t}^{M I N}$, and the latter captures how inflation expectations are updated when the information set is increased from $\mathcal{G}_{t}^{M I N}$ to any $\mathcal{G}_{t}^{P}$. Therefore, taking the stochastic 
process $\left\{\left(\pi_{t}, x_{t}\right)\right\}_{t=0}^{\infty}$ as given, the updating term represents the effects of information revelation.

The decomposition in (8) implies that the presence of the updating term increases the variability of the right-hand side, and hence that the social loss increases with information revelation. To see this, note that the original term is $\mathcal{G}^{M I N}$-adapted because cost-push shocks are $\mathcal{G}^{M I N}$-adapted, whereas the updating term is orthogonal to $\mathcal{G}_{t}^{M I N}$. The variance of the right-hand side of (8) is thus the sum of the variances of the original and the updating terms, which is minimized when $\mathcal{G}_{t}^{P}=\mathcal{G}_{t}^{M I N}$. Roughly speaking, if $\mathcal{G}_{t}^{M I N} \subset \mathcal{G}_{t}^{P}$, the updating term effectively acts as an additional orthogonal disturbance term in the New Keynesian Phillips curve, which exacerbates the inflation-output tradeoff the central bank faces. Therefore, any information that helps predict future inflation is harmful for ex ante welfare. ${ }^{11}$

Figures 1 and 2 illustrate this point graphically. Suppose that the distribution of $p u_{t+1}$ is exogenously fixed. On the horizontal axis is $\pi_{t}-\kappa x_{t}$, which equals the sum of the discounted expected inflation and the mark-up shock, $\beta \mathbb{E}^{P}\left[\pi_{t+1}\right]+u_{t}$. We also draw the loss function $L$ as a symmetric function around its minimizer. Figure 1 illustrates a situation where the private sector is endowed with $\mathcal{G}^{M I N}$ and the term $\beta \mathbb{E}\left[\pi_{t+1} \mid \mathcal{G}_{t}^{M I N}\right]+u_{t}$ can take on two values that are symmetric around the minimizer of $L$, with equal probability. Then it is straightforward that the ex-ante loss is at the level indicated in the figure. In Figure 2, the private sector is better informed, and is endowed with $\mathcal{G}$ with $\mathcal{G}^{M I N} \subset \mathcal{G}^{P}$. How is $\beta \mathbb{E}\left[\pi_{t+1} \mid \mathcal{G}_{t}^{P}\right]+u_{t}$ distributed? Because its conditional mean given $\mathcal{G}_{t}^{M I N}$ equals $\beta \mathbb{E}\left[\pi_{t+1} \mid \mathcal{G}_{t}^{M I N}\right]+u_{t}$, it must be distributed around $\beta \mathbb{E}\left[\pi_{t+1} \mid \mathcal{G}_{t}^{M I N}\right]+u_{t}$. Figure 2 depicts such a situation, where $\beta \mathbb{E}\left[\pi_{t+1} \mid \mathcal{G}_{t}^{P}\right]+u_{t}$ is distributed symmetrically around $\beta \mathbb{E}\left[\pi_{t+1} \mid \mathcal{G}_{t}^{M I N}\right]+u_{t}$. The ex-ante loss is larger when the private sector is better informed than when it is less informed. This implies that the

\footnotetext{
${ }^{11}$ Wohltmann and Winkler (2008) obtain a similar result in a perfect foresight economy. They derive ex post welfare under optimal policy when a cost-push shock hits in a known period $T$. They find that welfare loss is minimized at $T=0$ unless prices are implausibly flexible, and offer intuition along the lines of ours. However, under the assumption of perfect foresight, agents always perfectly anticipate an infinite sequence of cost-push shocks, regardless of the value of $T$. The effect they identify is not that of anticipation of future shocks, but rather that of the delayed materialization of a shock. Our framework is more suitable to analyze the role of the anticipation of future shocks, because the shock process is held fixed and only the private agents' information set is affected by the signal structure, and is more general because it permits, e.g., imperfect signals.
} 


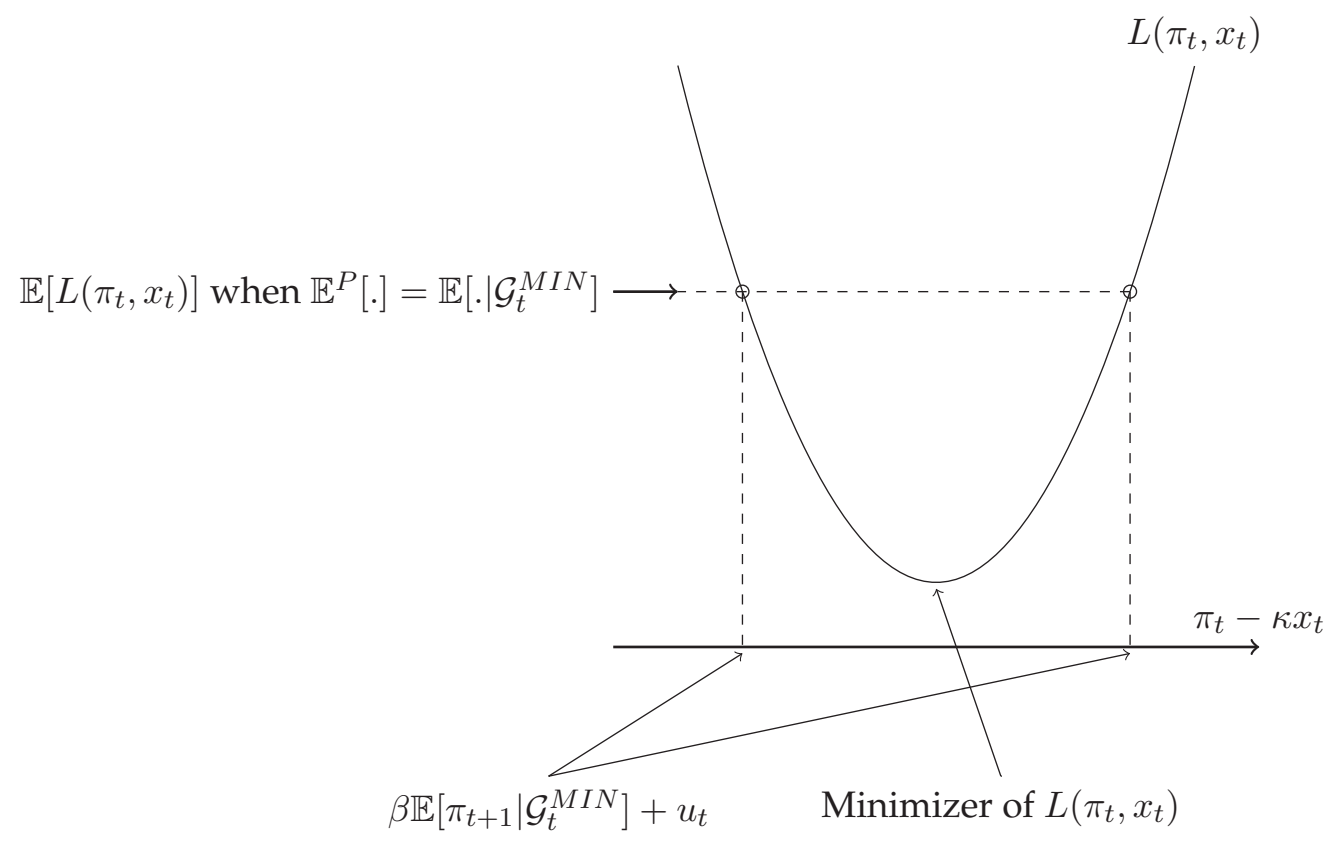

Figure 1: The inflation vs. the output gap trade-off when the private sector is uninformed

distribution of $\pi_{t}-\kappa x_{t}$ when the private sector is better informed is a mean-preserving spread of the distribution when the private sector is less informed. Because the loss function is convex, a mean-preserving spread is undesirable.

\subsubsection{Bayesian persuasion}

Our results are closely related to the literature of Bayesian persuasion. In this literature, the informed party (Sender) commits to a signal-generating device before observing private information, and the uninformed party (Receiver) takes an action after observing a signal. A signal affects Receiver's action through his posterior belief. Whether disclosure benefits Sender depends on how her payoff changes with Receiver's posterior belief. Kamenica and Gentzkow (2011) has shown that Sender benefits from disclosure if her expected payoff written as a function of Receiver's posterior belief is non-concave, because disclosure amounts to "concavify" such a payoff function. 


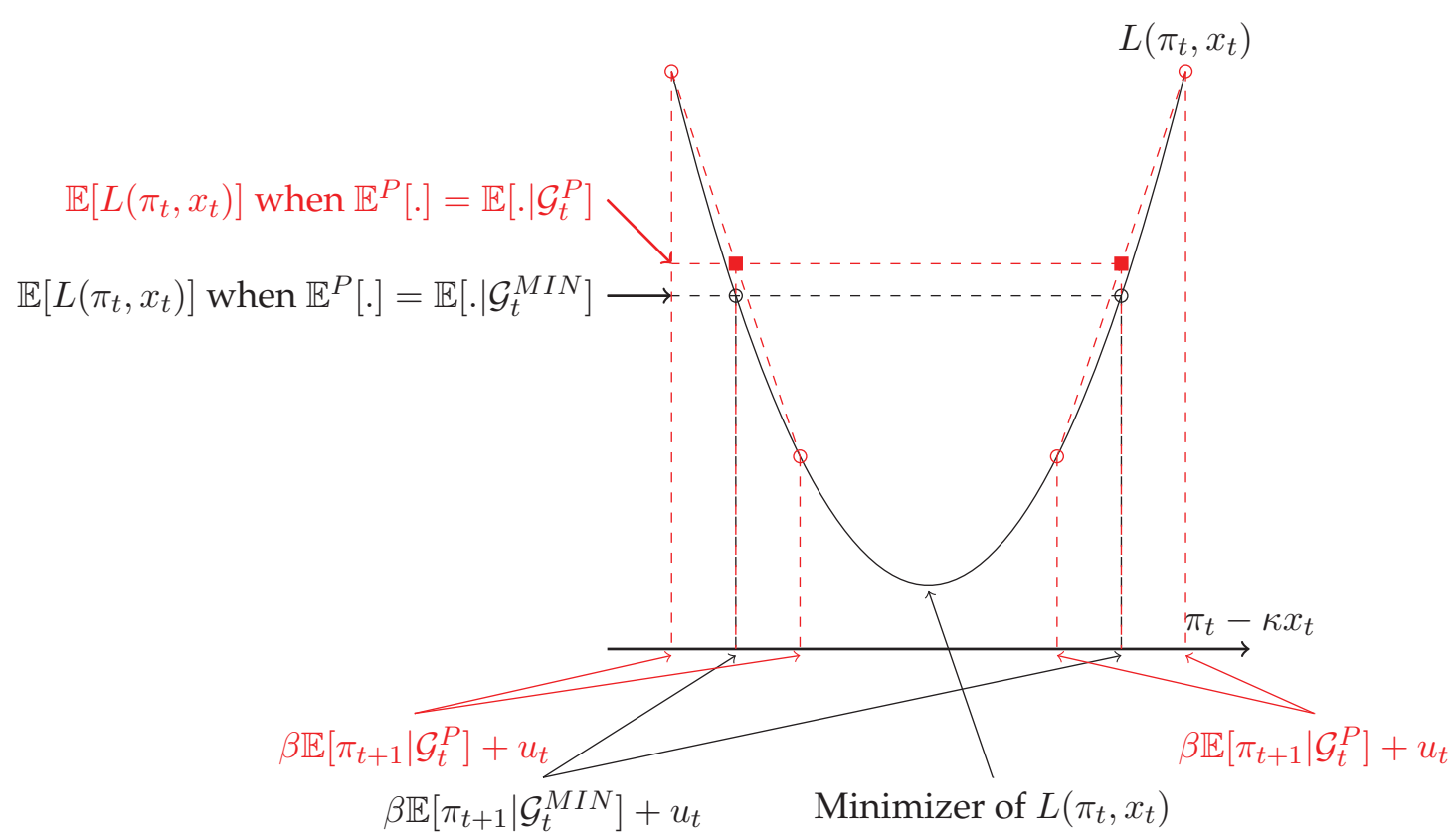

Figure 2: The inflation vs. the output gap trade-off when the private sector is betterinformed

In our model, Sender is the central bank and Receiver is the private agents. Figures 1 and 2 have shown that the loss function $L\left(x_{t}, \pi_{t}\right)$ varies as we vary the information set of the private agents in period $t$, holding the probability distribution of $\pi_{t+1}$ fixed. As expected inflation is a linear function of posterior, they effectively demonstrate that Sender's payoff is a strictly concave function when written as Receiver's posterior.

Therefore our result can be interpreted as an application of Bayesian persuasion to a macroeconomic question of forward guidance. However, our model differs from standard models in the Bayesian persuasion literature: the central bank not only sends messages but also sets interest rates that affect Receiver's incentives, and Receiver is not a single agent but atomless private agents that interact with each other and with the central bank through markets. Despite these differences, the basic insight of Bayesian persuasion holds true.

Fujiwara and Waki (forthcoming) use a neoclassical growth model without nominal rigidities to analyze the welfare effect of forward guidance about future fiscal shocks. They find that the optimal disclosure policy features selective transparency 
- forward guidance should be transparent about future non-distortionary spending shocks while secretive about future distortionary tax shocks. In contrast to the present paper in which the New Keynesian Phillips curve is crucial for the optimality of non-transparency, the key mechanism in their paper is the Euler equation that can be distorted by future taxes.

\subsubsection{Where do the gains from better information go?}

If the private sector obtains more information, it may appear that private agents both the household and goods producers - must not lose anything because they can still choose not to use the additional information. This assertion is incorrect because the price setters' incentives are not perfectly aligned with the household's (i.e., social welfare) or with the central bank's. Price setters in a Calvo model do not internalize the inefficiency associated with price dispersion and their profit-maximizing responses to news shocks increase expected inefficiency.

To see this, consider a benevolent central bank that minimizes the loss in (4). Ideally, it wants to conduct policy so that both inflation and the output gap are always zero. For any given process of inflation and any information the household has, the central bank can indeed conduct policy so that the output gap is always zero. However, there is an incentive for the price setters to deviate from price stability even if the output gap is fully stabilized at zero, when a mark-up shock and inflation expectations deviate from zero. In this sense, price setters' incentives are not aligned with the social objective. ${ }^{12}$ When price setters have more information about future shocks, they tailor their current prices based on additional information to increase profits. ${ }^{13}$ However, as a result, prices then tend to move with future shocks and social welfare decreases.

\footnotetext{
${ }^{12}$ This is the reason why the optimal commitment policy problem has to take the New Keynesian Phillips curve, which summarizes price setters' incentives, as a constraint.

${ }^{13}$ The price setters take certain prices as given, e.g., the aggregate nominal price, the real wage, etc. Taking these prices as given, the profits of the price setters weakly increase with information they possess. Because these objects change in an equilibrium when all firms change their prices using additional information, the price setters' equilibrium profits may not increase.
} 


\subsection{Time-inconsistency of secrecy}

Importantly, the optimal secretive commitment policy is time-inconsistent for two reasons. One reason is standard in the New Keynesian literature - the optimal commitment policy depends on history which the optimal discretionary policy ignores. The other reason is unique to the present setting - commitment to secrecy is by itself time-inconsistent.

To see this, consider the example in Section 2.2. Again we assume that $x_{t}$ is always set to zero and compare inflation for $n=0$ and for $n=1$ :

$$
\pi_{t}= \begin{cases}u_{t}, & \text { if } n=0, \\ u_{t}+\beta u_{t+1}, & \text { if } n=1\end{cases}
$$

As illustrated in Section 2.2, the ex ante welfare loss is bigger when $n=1$. Still, the central bank can find it optimal, ex post, to convey true information about $u_{t+1}$. Imagine that a realized value of $\left|u_{t}+\beta u_{t+1}\right|$ happens to be smaller than the realized value of $\left|u_{t}\right|$. In this case, price setters' price changing incentives are smaller when they can observe the next period shock. Conditional on such an event, ex post welfare loss in period $t, \pi_{t}^{2}$, is lower for $n=1$ and the central bank is tempted to reveal its private information about the next period shock. Hence, in addition to the time inconsistency problem for commitment policy that is well known in New Keynesian models, there is also the time inconsistency problem in communication policy.

\subsection{Extensions}

Commitment to secrecy remains optimal even if we augment the model with an effective lower bound on the nominal interest rate and with a shock to the social loss function.

\subsubsection{A New Keynesian model with the zero lower bound}

We use a model along the lines of Eggertsson and Woodford (2003) and Adam and Billi (2006), in which the zero lower bound on nominal interest rates can bind when a large, negative shock to the natural rate of interest hits the economy. Our model 
is more general than the conventional, simple one. The zero lower bound may bind multiple times and may not be binding at time 0 , and the central bank can act differently when it foresees that the zero bound will bind or that it will cease to bind in the near future.

The Ramsey problem is the same as before except that it must respect the nonnegativity constraint on nominal interest rates:

$$
i_{t} \geq 0
$$

An optimal secretive commitment policy is $\left\{\left(\pi_{t}^{S E C}, x_{t}^{S E C}, i_{t}^{S E C}\right)\right\}_{t=0}^{\infty}$ that minimizes the loss function (3) subject to the New Keynesian Phillips curve in (5), the dynamic IS equation in (6), and the zero lower bound (ZLB) constraint in (9). Then we have the following result:

Corollary 2 Proposition 1 and Corollary 1 hold in the presence of the zero lower bound.

Our proof of Proposition 1 is valid in the presence of the ZLB because the $\left\{\tilde{i}_{t}\right\}$ we have constructed satisfies the ZLB if $\left\{i_{t}\right\}$ does.

This proposition implies that, from the ex ante point of view, the central bank should be secretive even if the zero lower bound is already binding at time 0 and if it may, for example, receive private news that a negative natural rate shock disappears in near future or that a future cost-push shock is positive. This might appear to contradict with the literature, which has shown that raising inflation expectations can be welfare-improving at the zero lower bound, but it is not. From the ex post point of view, once the central bank observes, e.g., the short duration of a negative natural rate shock or a positive future cost-push shock, ex post welfare improves if the private sector is also informed about the information. However, from the ex ante point of view, the duration of a negative natural rate shock may be much longer and a future cost-push shock may be negative; transparency lowers ex post welfare in that scenario. On average, it is better to leave the private sector uninformed. 


\subsubsection{Private news about the central bank's future policy goals}

Delphic forward guidance can be used to communicate information not only about future cost-push shocks but also about the central bank's objective in the future. Let $\left\{\theta_{t}\right\}_{t=0}^{\infty}$ be an exogenous stochastic process. Ex ante welfare loss is now given by

$$
\mathbb{E}\left[\sum_{t=0}^{\infty} \delta^{t} L\left(\pi_{t}, x_{t}, \theta_{t}\right)\right] .
$$

A quadratic example such as

$$
L(\pi, x, \theta)=\frac{1}{2}\left[(\pi-\theta)^{2}+b x^{2}\right], \quad b \geq 0,
$$

is used elsewhere in the literature, e.g., Stein (1989), Moscarini (2007), Athey, Atkeson, and Kehoe (2005), and Waki, Dennis, and Fujiwara (2018). Jensen (2002) instead assumes $\theta$ hits the central bank's target output gap. The shock may be two dimensional, $\theta=\left(\theta^{\pi}, \theta^{x}\right)$, and $L(\pi, x, \theta)=\left[\left(\pi-\theta^{\pi}\right)^{2}+b\left(x-\theta^{x}\right)^{2}\right] / 2$, or it may hit the relative weight of the output gap in the loss function.

Proposition 2 Suppose that $\theta_{t}$ is observed by the private sector at the beginning of period $t$. Then Proposition 1 and Corollary 1 hold in the presence of shocks to the social welfare function.

If $\theta_{t}$ is publicly observed at the beginning of period $t$, we can replace equation (7) in the proof of Proposition 1 to

$$
\begin{aligned}
\mathbb{E}\left[L\left(\pi_{t}, x_{t}, \theta_{t}\right)\right] & =\mathbb{E}\left[\mathbb{E}\left[L\left(\pi_{t}, x_{t}, \theta_{t}\right) \mid \mathcal{G}_{t}^{M I N}\right]\right] \\
& \geq \mathbb{E}\left[L\left(\mathbb{E}\left[\pi_{t} \mid \mathcal{G}_{t}^{M I N}\right], \mathbb{E}\left[x_{t} \mid \mathcal{G}_{t}^{M I N}\right], \theta_{t}\right)\right]=\mathbb{E}\left[L\left(\tilde{\pi}_{t}, \tilde{x}_{t}, \theta_{t}\right)\right]
\end{aligned}
$$

and Proposition 2 follows.

Our focus on the future shock is crucial for this result. When a contemporaneous shock to $\theta$ is observed by the central bank but not by the private sector, then the central bank generally faces a trade-off: there are gains from making period- $t$ actions contingent on $\theta_{t}$, but that can reveal to the private sector some information about $\theta_{t}$ and possibly about future $\theta^{\prime}$ s, which is detrimental to welfare. Therefore, for contemporaneous shocks, secrecy is not in general optimal. 
In contrast to Moscarini (2007), the precision of the private information possessed by the central bank is irrelevant for this result. He finds that, under discretion, the competence of a central bank, measured by the precision of the private signal the central bank receives about a contemporaneous shock to its objective, implies improved welfare. A crucial difference is that his result is about a contemporaneous private shock, while ours is about private news. Also, the Phillips curve in his model is not a forward-looking New Keynesian one and, therefore, information about future shocks does not directly affect a current Phillips curve.

Jensen (2002), using a two-period New Keynesian model where the central bank has an objective function that differs from social welfare and is unable to commit, also finds that transparency is not always desirable. The central bank's private information in his model is the permanent shock that introduces the wedge between the socially desirable output gap and the central bank's preferred output gap and, hence, is not private news. The reason behind the undesirability of transparency is also different from our paper. In our model, more information about future shocks adds orthogonal fluctuations in inflation expectations. In his model, more precise information about the central bank's preference introduces positive correlation between the current output gap and inflation expectations. It exacerbates the response of inflation, and the central bank finds it optimal to dampen the responses of the output gap to its preference shocks and to cost-push shocks. Transparency is therefore useful to discipline the central bank's actions when its objective is sufficiently different from social welfare, but harmful when it is not.

Waki, Dennis, and Fujiwara (2018) consider a monetary-policy delegation problem in a New Keynesian model, when the contemporaneous shock is private information to the central bank and influences the central bank's loss as in (11), and the central bank is unable to commit. Their paper differs from ours in that the central bank does not possess private news in their model, and their focus is on the optimal legislation to be imposed on the central bank's choice.

\subsubsection{Non-optimal monetary policy rule}

In Appendix A.2, we confirm the undesirability of information revelation when the nominal interest rate follows a Taylor rule. Bianchi and Melosi (2018) compare trans- 
parency and no transparency when the monetary policy follows a Taylor rule whose coefficients change according to a Markov chain. They find welfare gains from transparency, but their welfare criterion is steady state welfare, not ex ante welfare. We compare our paper with theirs in more details in Appendix A.2.

\subsubsection{Optimal discretionary policy}

The present paper focuses on the full commitment case, but we analyze the optimal discretionary policy for a given information structure in Appendix A.3. The question we ask is this: can information revelation be beneficial when the central bank is unable to commit to a state-contingent action plan but is able to commit to information revelation policy? Again, the answer is no.

When is it reasonable to assume that the central bank can commit to secrecy but cannot commit to a state-contingent policy? This assumption can be justified if, every period, the central bank chooses whether to observe a piece of private news or not. This is a situation in which private news can be observed by the central bank only after it does some "research." In such an environment, the central bank is effectively able to commit to secrecy by choosing not to do research, even if it is unable to commit to future policy actions.

Even when the central bank is unable to commit to not observing the private news, if the private news is not verifiable, non-revelation can be an equilibrium outcome. This is because in cheap-talk games there is always a "babbling" equilibrium, in which no information is transmitted. In a babbling equilibrium, the central bank sends a message independently from its private information, and the private sector never updates its belief in response to the received message. These strategies are mutually best response, and the central bank has no incentive to reveal information because it won't have any effects on the private sector's actions.

\section{Numerical results}

Now we examine how ex ante welfare changes when the private sector becomes better informed about future disturbances in three different models. In all numerical 
experiments, the private sector is assumed to observe the $n$-period ahead shocks, and we examine how ex ante welfare changes as we increase $n$.

We begin by characterizing optimal commitment policy in two linear-quadratic New Keynesian models. The first model is the one introduced in Section 2, and the second one is the model with endogenously accumulated capital analyzed in Edge (2003) and Takamura, Watanabe, and Kudo (2006). In both models, we exclusively focus on a markup shock, which introduces a wedge between the social objective and the price setters' incentives.

These two models are much simpler than the models used for forecasting and policy simulation in many policy institutions. Hence, we also investigate whether secrecy remains optimal in a more elaborate DSGE model that is based on Christiano, Eichenbaum, and Evans (2005) and Smets and Wouters (2003, 2007). Contrary to the previous experiments, the model incorporates multiple frictions and shocks, and the nominal interest rate is set according to a Taylor rule. Multiple distortions lead to complex relationship among distortions, which may be alleviated by the announcement of future distortionary shocks.

Throughout the numerical experiments, we compute ex ante welfare loss as follows. We first obtain the welfare loss conditional on period-0 information - initial values of the endogenous state variables and the realization of shocks from period 0 to period $n$ - and then take expectations over the shocks.

\subsection{Standard linear-quadratic New Keynesian model}

The central bank minimizes the quadratic loss in (4) subject to the New Keynesian Phillips curve in (1), where $\mathbb{E}\left[\pi_{t+1} \mid \mathcal{G}_{t}^{P}\right]$ is set to $\mathbb{E}\left[\pi_{t+1} \mid u_{0}, u_{1}, \ldots, u_{t+n}\right]$.

Parameters are calibrated as in Table 1. Parameters $\sigma, \eta, \varepsilon$ and $\theta$ denote the inverse of the intertemporal elasticity of substitution, the inverse of Frisch elasticity, the elasticity of substitution among differentiated products, and the Calvo parameter. $1-\theta$ is the probability of re-optimization of prices. The standard deviation of the cost-push shock is set to $1 \%$. Parameter $\kappa$ is related to structural parameters as: $\kappa \equiv(1-\theta)(1-\beta \theta)(\sigma+\eta) /\{\theta(1+\eta \varepsilon)\}$. 
Table 1: Parameter Values

\begin{tabular}{lll}
\hline Parameters & Values & Explanation \\
\hline$\beta$ & .99 & Subjective discount factor \\
$\sigma$ & 1 & Inverse of intertemporal elasticity of substitution \\
$\eta$ & 1 & Inverse of Frisch elasticity \\
$\varepsilon$ & 6 & Elasticity of substitution among differentiated products \\
$\theta$ & .75 & Calvo parameter \\
\hline
\end{tabular}

\subsubsection{Results}

Figure 3 shows how ex ante welfare ( -1 times the quadratic loss in (4)) under commitment and under discretion changes with $n$ (shown on the horizontal axis). The case in which $n=0$ corresponds to the situation in which the private sector only observes the contemporaneous cost-push shock. As we have shown theoretically, ex ante welfare is maximized when $n=0$ and monotonically decreases with $n$, under both commitment and discretion.

The relative welfare loss from discretionary monetary policy is larger when costpush shocks in the more distant future become observable by the private sector. The intuition behind this result is simple. When the private sector observes more distant future cost-push shocks, it is desirable, from an ex ante point of view, for the central bank to reduce the dependence of future inflation on cost-push shocks that are foreseen. This is because this dependence acts as a disturbance to the New Keynesian Phillips curve. Such a reduction is possible only when the central bank can commit. Therefore the loss under discretion increases faster than the loss under commitment, as $n$ increases. This finding reiterates the importance of commitment in New Keynesian models.

Notice that the usual welfare cost of lack of commitment is the difference between the two lines in Figure 3 at $n=0$. The welfare cost of one-period-ahead information revelation under commitment (a decline in welfare when $n$ is changed from 0 to 1 ) is about twice as large. Hence, as long as we view gains from commitment as being important, we must also view gains from secrecy as being important.

Figure 4 draws impulse responses to an anticipated positive 1\% cost-push shock. In each panel, the period when the cost-push shock materializes corresponds to 0 on 


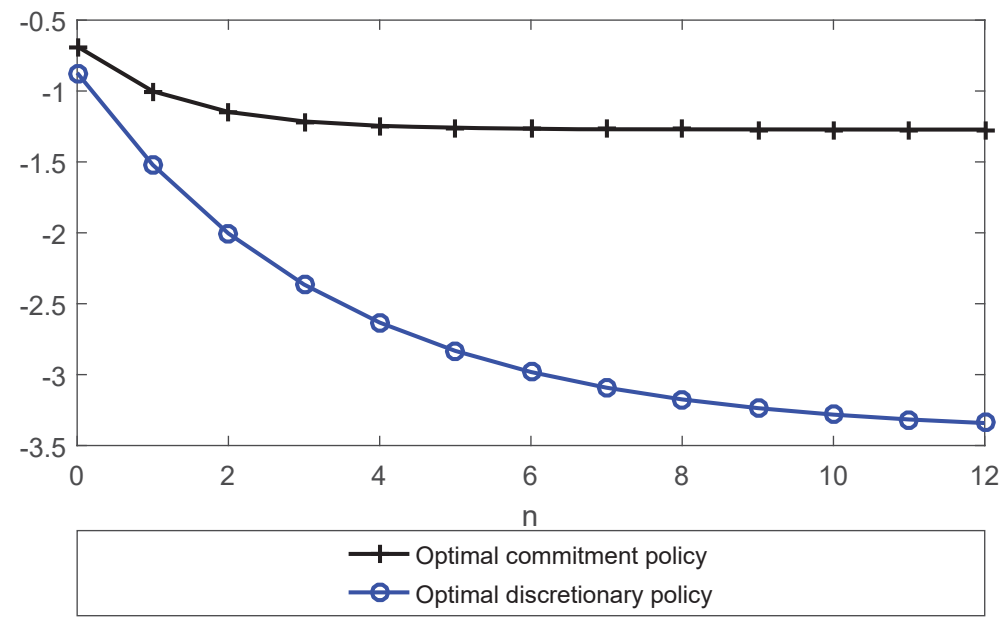

We plot ex ante welfare, i.e., the welfare loss in equation (4) times -1. We further re-scale the loss function by multiplying by a constant so that the ex ante loss from a permanent one percent inflation and the zero output gap with certainty is one.

Figure 3: Ex ante welfare under commitment and discretion

the $\mathrm{x}$-axis. We display the responses to the news shock from $n=0$ to 4 . The left two panels depict the responses of inflation and the output gap under discretion, and the right panels depict those under commitment.

Responses under discretion offer an intuitive explanation as to why there is no gain from revealing private news. Observe that, irrespective of whether a shock is anticipated or not, responses after the materialization of shocks are identical. Under optimal discretionary policy, revealing future cost-push information only results in additional fluctuations before the realization of the shock, and therefore is undesirable.

In contrast, under commitment, the central bank can lower the inflation response upon the materialization of a shock by altering the inflation responses after the materialization and the output gap responses. It is clear in Figure 4 that the size of the inflation response in the period when the shock is realized decreases with $n$. Because 

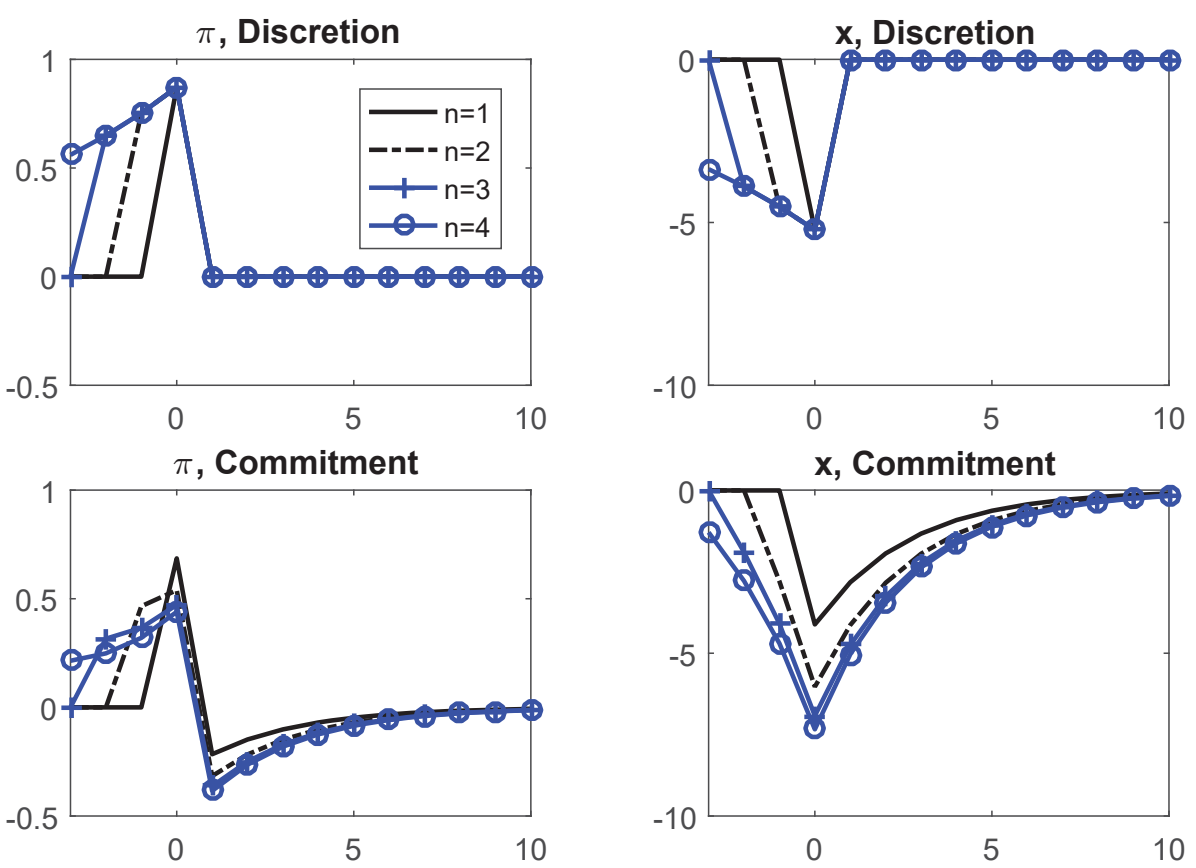

On the horizontal axis is the number of periods since the materialization of a one percent shock, i.e., the shock materializes at zero. When $n>0$, endogenous variables react before the materialization.

Figure 4: Impulse Responses: Discretion vs. Commitment

the New Keynesian Phillips curve must be satisfied, lower contemporaneous inflation response can be achieved only by moving future inflation and the output gap further in the negative direction, which is inefficient.

\subsection{Endogenous Capital}

Next, we examine the linear quadratic model with endogenous capital accumulation in Edge (2003) and Takamura, Watanabe, and Kudo (2006). The model is a straightforward extension of the New Keynesian model to incorporate endogenous capital formation subject to the convex capital adjustment costs: $\bar{I}_{t}=I\left(\bar{K}_{t+1} / \bar{K}_{t}\right) \bar{K}_{t}$, where $I(1)=\delta, I^{\prime}(1)=1$, and $I^{\prime \prime}(1)=\varepsilon_{\psi}$. Variables with upper bars denote level variables, 
while those without it are log deviations from their steady state values.

The benevolent central bank's ex ante loss function is derived as a second-order approximation of the representative household's utility:

$$
\mathbb{E} \sum_{t=0}^{\infty} \beta^{t}\left[\begin{array}{l}
(\sigma+\omega) Y_{t}^{2}+\sigma k^{2}\left[K_{t+1}-(1-\delta) K_{t}\right]^{2} \\
+\varepsilon_{\psi} k\left(K_{t+1}-K_{t}\right)^{2}+\rho_{k} k\left[\beta^{-1}-(1-\delta)\right] K_{t}^{2} \\
-2 \sigma k Y_{t}\left[K_{t+1}-(1-\delta) K_{t}\right]-2(\omega-\eta) Y_{t} K_{t} \\
+\left[\theta \varepsilon\left\{\rho_{k}+\left(\rho_{y}-\omega\right) \eta \epsilon\right\} /\left\{\rho_{k}(1-\theta)(1-\beta \theta)\right\}\right] \pi_{t}^{2}
\end{array}\right],
$$

subject to the New Keynesian Phillips curve:

$\pi_{t}=\beta \mathbb{E}\left[\pi_{t+1} \mid \mathcal{G}_{t}^{P}\right]+\frac{(1-\theta)(1-\beta \theta)}{\theta \psi}\left[(\omega+\sigma) Y_{t}-\sigma k K_{t+1}+\{\sigma k(1-\delta)-\omega+\eta\} K_{t}\right]+u_{t}$,

and the resource constraint:

$$
\begin{aligned}
0 & =Y_{t}+\frac{\rho_{y}[1-\beta(1-\delta)]-\sigma \beta(1-\delta)}{\sigma} \mathbb{E}\left[Y_{t+1} \mid \mathcal{G}_{t}^{P}\right]+\frac{k \sigma(1-\delta)+\varepsilon_{\psi}}{\sigma} K_{t} \\
& -\frac{\sigma k+\varepsilon_{\psi}(1+\beta)+\sigma \beta k(1-\delta)^{2}+\rho_{k}[1-\beta(1-\delta)]}{\sigma} K_{t+1}+\frac{\beta\left[\sigma k(1-\delta)+\varepsilon_{\psi}\right]}{\sigma} \mathbb{E}\left[K_{t+2} \mid \mathcal{G}_{t}^{P}\right],
\end{aligned}
$$

where $Y_{t}$ denotes output. Again, $\mathbb{E}\left[. \mid \mathcal{G}_{t}^{P}\right]$ equals $\mathbb{E}\left[. \mid u_{0}, u_{1}, \ldots, u_{t+n}\right] .^{14}$

Parameters are taken from Woodford (2005) and Takamura, Watanabe, and Kudo (2006) as in Table 2. Other parameters are defined as the function of structural parameters: $\rho_{y}:=\eta \phi_{h}+\omega_{p} \phi_{h} /\left(\phi_{h}-1\right), \rho_{k}:=\rho_{y}-\eta, k:=\left(1-\phi_{h}^{-1}\right) /\left\{\beta^{-1}-(1-\delta)\right\}, \omega:=\omega_{\omega}+\omega_{p}$, $\omega_{\omega}:=\eta \phi_{h}$, and $\psi:=1+\varepsilon\left(\rho_{y}-\omega\right) \eta / \rho_{k}$.

\subsubsection{Results}

Figure 5 compares the impulse responses for different $n$ 's. The responses of infla-

\footnotetext{
${ }^{14}$ We will also show impulse responses of real marginal costs $M C_{t}$ and investment $I_{t}$, which are given by:

$$
M C_{t}=(\omega+\sigma) Y_{t}-\sigma k K_{t+1}+[\sigma k(1-\delta)-\omega+\eta] K_{t},
$$
}

and

$$
I_{t}=k\left[K_{t+1}-(1-\delta) K_{t}\right]
$$


Table 2: Parameter Values: Endogenous Capital

\begin{tabular}{lll}
\hline Parameters & Values & Explanation \\
\hline$\beta$ & .99 & Subjective discount factor \\
$\sigma$ & 0.6 & Inverse of intertemporal elasticity of substitution \\
$\eta$ & .11 & Inverse of Frisch elasticity \\
$\varepsilon$ & $23 / 3$ & Elasticity of substitution among differentiated products \\
$\theta$ & .75 & Calvo parameter \\
$\delta$ & $.12 / 4$ & Depreciation rate \\
$\phi_{h}$ & $4 / 3$ & $\begin{array}{l}\text { Reciprocal of the elasticity of the production function } \\
\text { with respect to labor input }\end{array}$ \\
$\varepsilon_{\psi}$ & 3 & Capital adjustment costs parameter \\
$\omega_{p}$ & .33 & Negative of the elasticity of the marginal product \\
\hline
\end{tabular}

tion and marginal cost are qualitatively similar to the model without capital, noting that the marginal cost is proportional to the output gap in the canonical model. The response of marginal cost is magnified as $n$ increases, and the inflation response upon the realization of a shock is reduced. However, it takes much longer for the impulse response of the marginal cost to come close to zero. This is due to the fact that marginal costs depend on capital that adjusts only slowly over time. The top-left panel shows that it takes a long time for capital to return to the steady-state level even if $n$ is low, and that the response of capital increases as $n$ increases. This slow-moving property of marginal costs keeps the inflation response away from zero, before and after the realization of a shock.

Figure 6 compares ex ante welfare for different values of $n$. Again the conditional loss is increasing in $n$, which is consistent with our theoretical results; i.e., there is an expected virtue of ignorance. Results are similar to those obtained from the standard New Keynesian model.

\subsection{A canonical DSGE model}

Now we turn to a canonical DSGE model based on Christiano, Eichenbaum, and Evans $(2005)$ and Smets and Wouters $(2003,2007)$ to examine whether secrecy remains optimal in a more elaborate model. ${ }^{15}$

\footnotetext{
${ }^{15} \mathrm{~A}$ complete description of the model is provided in Appendix A.4.
} 

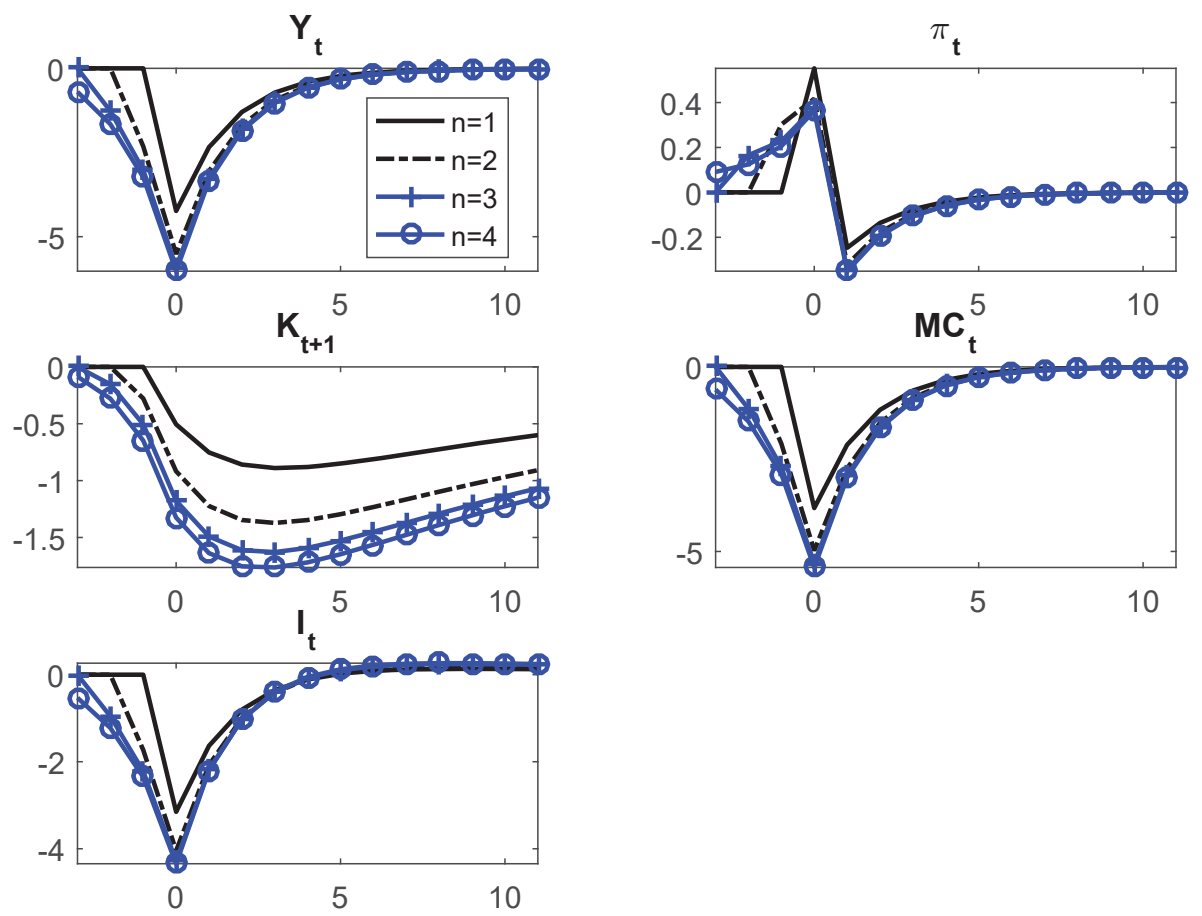

On the horizontal axis is the number of periods since the materialization of a one percent shock, i.e., the shock materializes at zero. When $n>0$, endogenous variables react before the materialization.

Figure 5: Impulse Responses: Endogenous Capital

There are three fundamental differences from the previous experiments. First, in addition to price rigidity, the model features distortions such as wage rigidity and the external habit in consumption. Frictions such as investment adjustment costs and price and wage indexation to past inflation are also introduced. Second, the nominal interest rate follows the Taylor type rule with inertia, instead of the optimal commitment policy. Third, we examine news about the technology shock, the wage markup shock, and the monetary policy shock, in addition to that about the cost-push shock, the implications of which have already been examined in detail. Parameters are set following Fujiwara, Hirose, and Shintani (2011) as in Table 2. We solve the model 


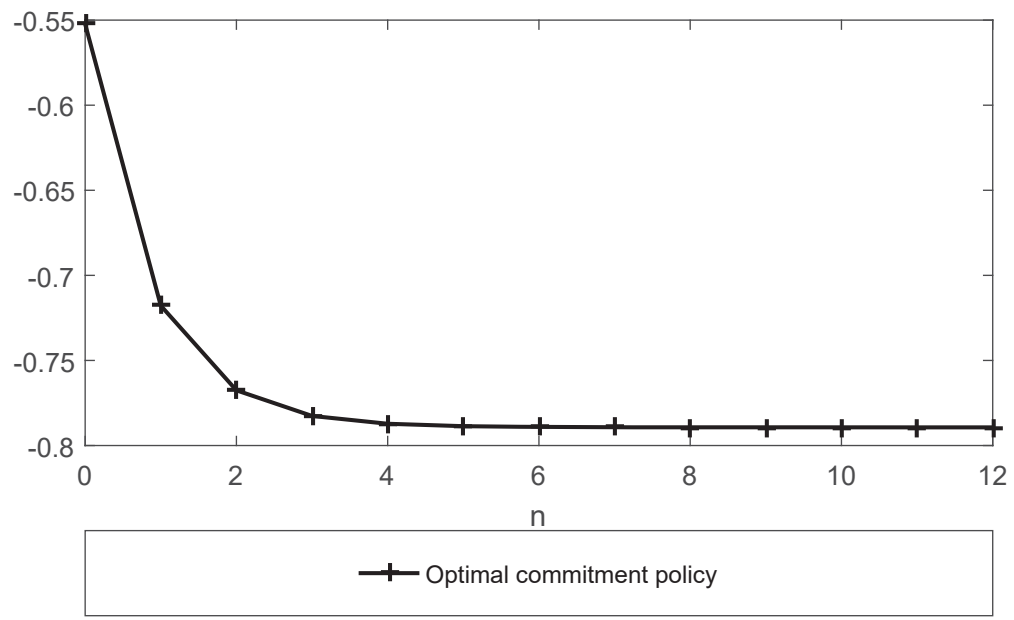

We plot ex ante welfare, i.e., the welfare loss in equation (12) times -1 . We further re-scale the loss function by multiplying by a constant so that the ex ante loss from a permanent one percent inflation and the zero gap for real variables with certainty is one.

Figure 6: Ex Ante Welfare: Endogenous Capital

using the second-order approximation.

Below, we first present the result in the full-blown model and then, by turning on and off some of the distortions and the frictions one at a time, demonstrate that none of the four news shocks we consider generates welfare gains consistently across different model specifications. This suggests that improving welfare through Delphic forward guidance is difficult particularly in the face of model uncertainty.

\subsubsection{Results}

Figure 7 displays how ex ante welfare changes as $n$ is increased from 0 for each of the four shocks. Welfare costs are measured in consumption equivalent variation (CEV) relative to when $n=0$. (See Appendix A.4.) Two observations are worth discussing. First, the welfare effect of each news shock may be either positive or negative. Hence, 
Table 3: Parameter Values

\begin{tabular}{lll}
\hline Parameters & Values & Explanation \\
\hline$\beta$ & .9983 & Subjective discount factor \\
$\sigma$ & 1.72 & Inverse of intertemporal elasticity of substitution \\
$\eta$ & 2.23 & Inverse of Frisch elasticity \\
$\epsilon$ & 10 & Elasticity of substitution among differentiated products \\
$\theta$ & .4 & Calvo parameter for price \\
$\delta$ & .025 & Depreciation rate \\
$s^{\prime \prime}$ & 4.82 & Investment growth adjustment costs \\
$b$ & .38 & Consumption habit \\
$\alpha$ & .21 & Capital share \\
$\theta_{h}$ & .26 & Calvo parameter for wage \\
$\gamma$ & .18 & Price indexation \\
$\gamma_{h}$ & .51 & Wage indexation \\
$\epsilon_{h}$ & 10 & Elasticity of substituion among differentiated labor \\
$\rho$ & .75 & Policy inertia \\
$\phi^{\pi}$ & 2.1 & Policy reaction to inflation rates \\
$\phi^{y}$ & .17 & Policy reaction to output growth \\
$\rho_{z}$ & .98 & AR(1) parameter for technology shock \\
$\rho_{u}$ & .86 & AR(1) parameter for price markup shock \\
$\rho_{\mu}$ & .96 & AR(1) parameter for wage markup shock \\
$\rho_{\eta}$ & .36 & AR(1) parameter for monetary policy shock \\
$\sigma_{z}$ & .0043 & Standard deviation of technology shock \\
$\sigma_{u}$ & .0014 & Standard deviation of price markup shock \\
$\sigma_{\mu}$ & .0022 & Standard deviation of wage markup shock \\
$\sigma_{\eta}$ & .0016 & Standard deviation of monetary policy shock \\
\hline & &
\end{tabular}



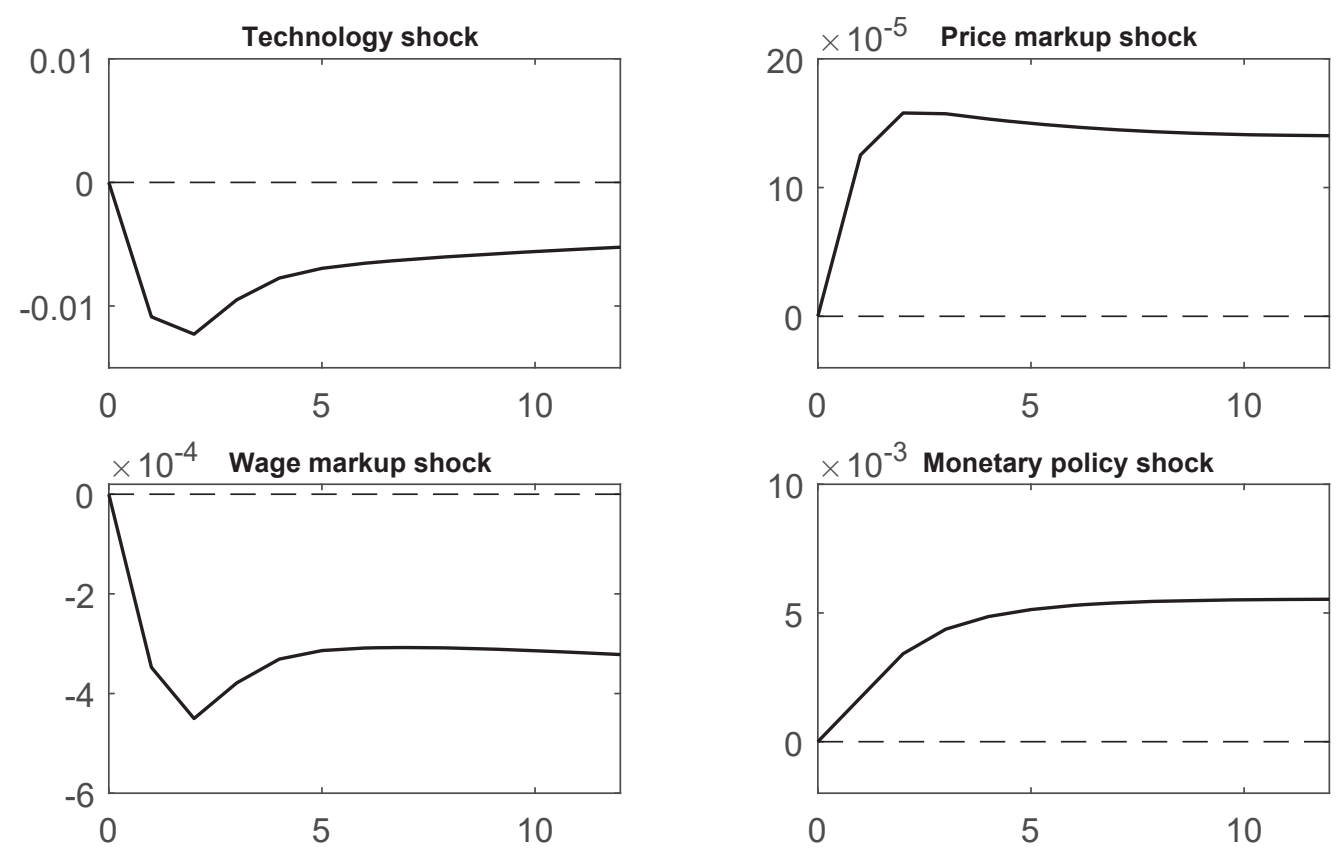

- ALL: Rigid P\&W + Inv. adj. costs + Ext. habit + policy inertia

Figure 7: Welfare Costs in CEV by News Horizon (\%): Full-blown model

the benefits and costs of transparency depend on the type of shock. For technology and wage markup shocks, ex ante welfare when future shocks are observed is lower than that when they are not observed, while for price markup and monetary policy shocks, the effect is opposite. Second, the welfare effect is not monotone in $n$, except for monetary policy shocks. For example, even for technology and wage markup shocks for which secrecy is optimal, increasing $n$ from 2 to a larger number improves ex ante welfare. Therefore, if the private sector already observes a two-period ahead shock, then conveying more information about these shocks can improve welfare.

Figure 8 compares the full-blown model to real models with neither price nor wage 
rigidity. The real models include a plain vanilla RBC model, the model with investment adjustment costs, and the model with both investment adjustment costs and external consumption habit. Unlike in the full-blown model, the technology news shock improves welfare in all these models. ${ }^{16}$ In the plain vanilla RBC model and the model with investment adjustment costs, a competitive equilibrium allocation is a solution to the social planner's problem in which the planner has the same information as the representative household. There is no misalignment of social and private incentives, and providing more information unambiguously improves welfare by allowing the household to make better decisions. Social and private incentives are not perfectly aligned in the model with the external consumption habit, but its effect on welfare is very small here.

Figure 9 displays the welfare effects of news shocks when we further add nominal rigidities. Here, the Taylor rule is not backward-looking and there is no policy inertia. In the top-left panel, the technology news shock is shown to lower welfare for these models when either price or wage rigidity is introduced on top of investment adjustment costs and external consumption habit. When we remove the investment adjustment costs, however, the welfare effect turns positive, implying that it is not the nominal rigidity but the combination of nominal rigidities and the investment adjustment costs that make the welfare effect of the technology news shock negative.

As shown in the bottom-left panel, the wage markup news shock generates negative welfare effects whenever the nominal wage is sticky. In contrast, the result is mixed for the price markup news shock. The welfare effect is negative when only prices are sticky, as we have found in a simple New Keynesian model, but turns positive when both price and wage are sticky. Quite naturally, as we lower the wage stickiness, welfare gains become smaller and turn negative eventually. Hence, sufficiently strong wage rigidity is necessary to improve welfare by Delphic forward guidance.

The bottom-left panel shows that the monetary policy news shock has negative welfare effects. The positive welfare effect of the monetary policy news shock in the full-blown model relies crucially on policy inertia.

Finally, Figure 10 shows the results when we further introduce policy inertia in

\footnotetext{
${ }^{16}$ Shocks to markups and to monetary policy do not affect an equilibrium in these models and therefore are not displayed.
} 


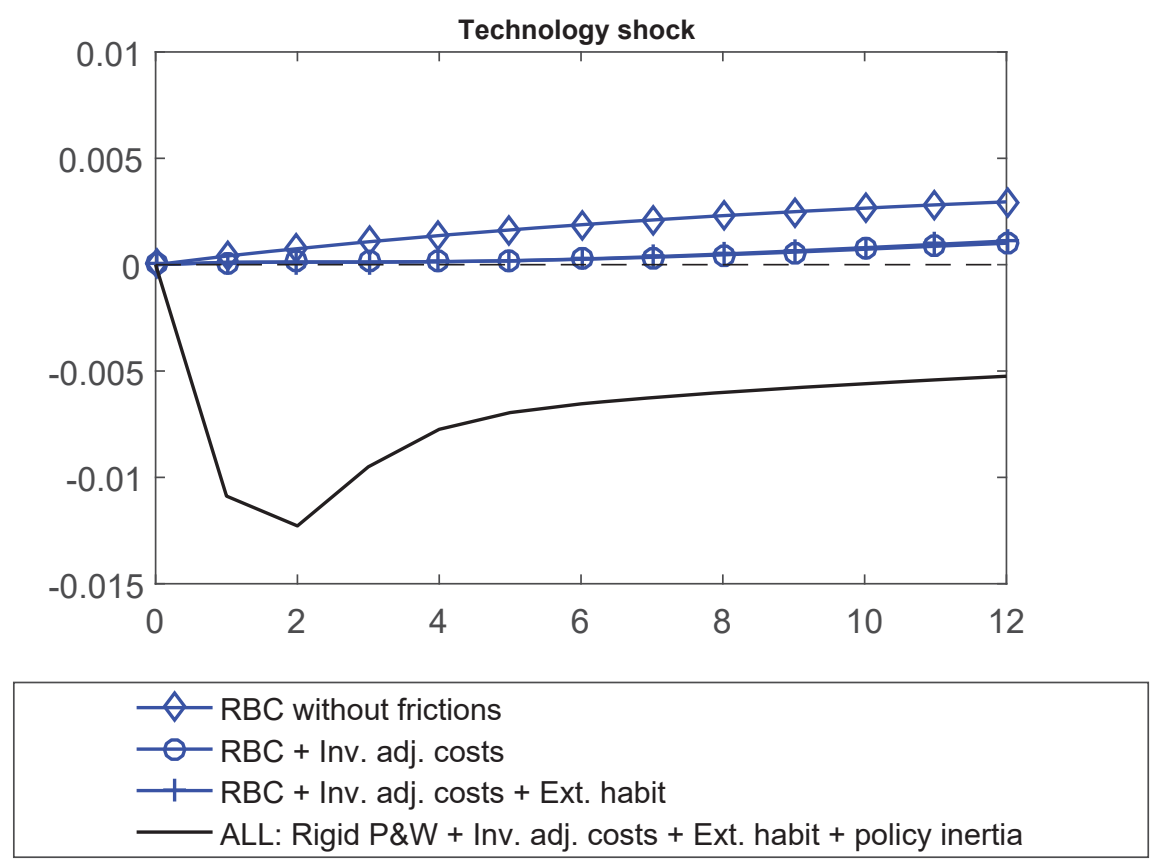

Figure 8: Welfare Costs in CEV by News Horizon (\%): Full-blown model vs. real models

the Taylor rule. The most significant difference from Figure 9 is found in the welfare effect of the monetary policy news shock in the bottom-left panel. The welfare effect turns positive when monetary policy has inertia. However, policy inertia itself is not sufficient to generate a positive welfare effect for the monetary policy news shock. In Appendix A.2 we show that in a three equation New Keynesian model with policy inertia the welfare effect of monetary policy news shock is negative. It is the interaction between policy inertia and other distortions that makes the welfare effect positive.

\subsubsection{What have we learned?}

In a more elaborate DSGE model, Delphic forward guidance can still be welfarereducing as in the simple model. Except for the wage-markup news shock that gen- 

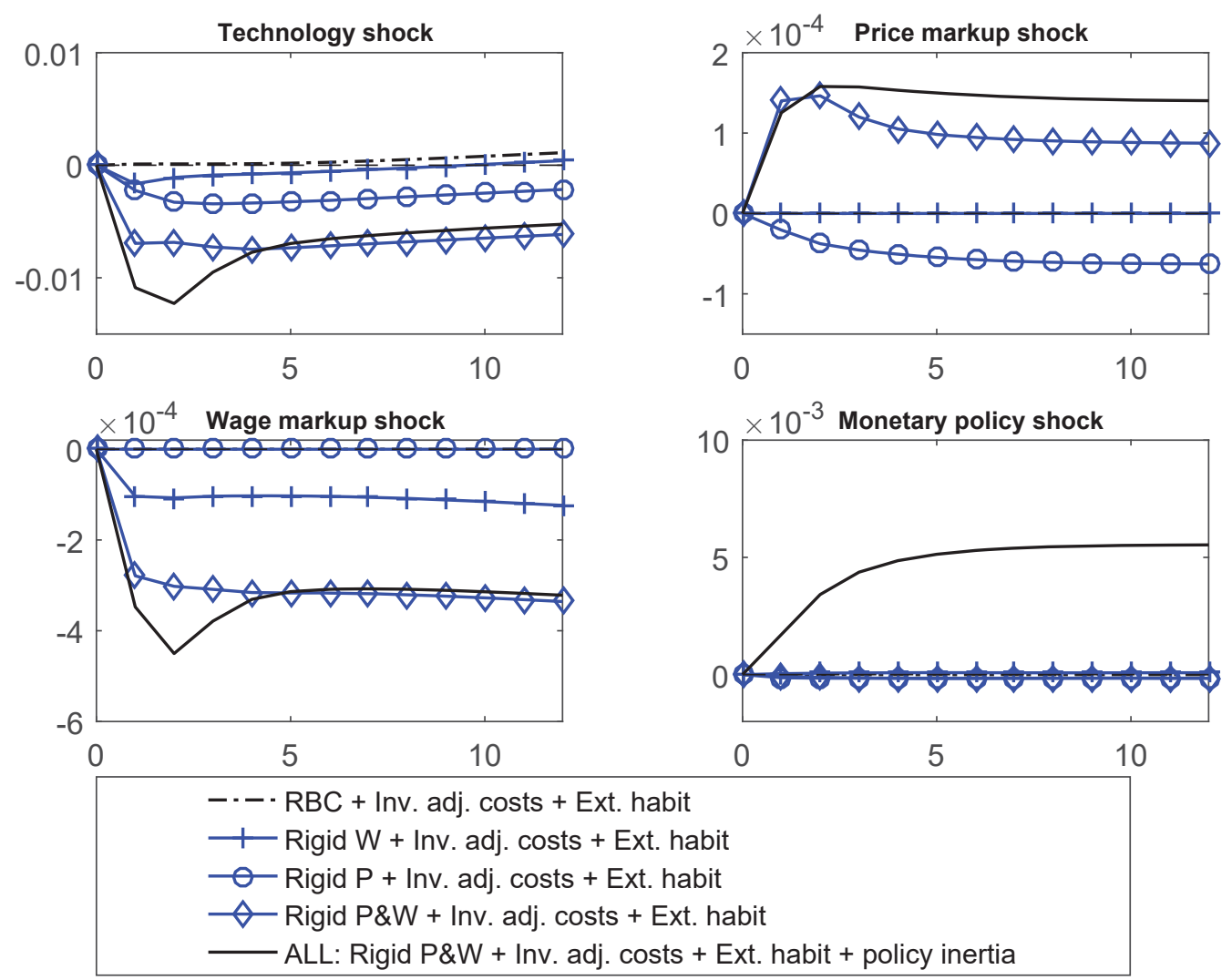

Figure 9: Welfare Costs in CEV by News Horizon (\%): Models with nominal rigidity but without policy inertia

erates welfare loss consistently across different models, whether the welfare effect of a news shock is positive or negative depends on the shock type as well as on the distortions and the frictions that are present in the model. Importantly, none of the four news shocks we have examined has robustly positive welfare effects across different model specifications.

In a frictionless model, Hirshleifer (1971) finds that access to better information before trading takes place will reduce risk-averse households' expected utility through higher variability of the prices of state-contingent claims, unless information itself is of direct social value. Our theoretical result in the simple New Keynesian model is 

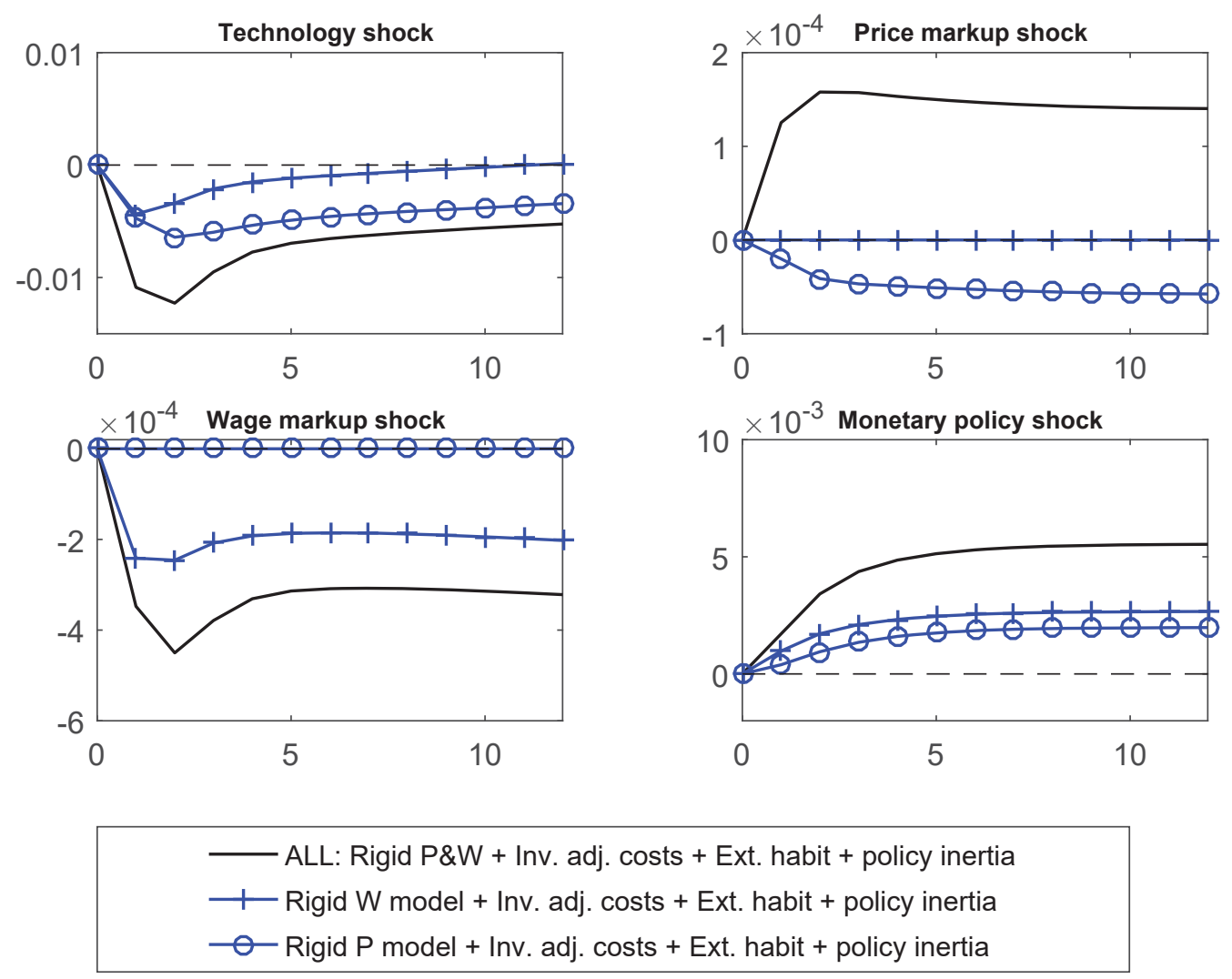

Figure 10: Welfare Costs in CEV by News Horizon (\%): Models with nominal rigidity but with policy inertia

consistent with this: the cost-push shock does not have social value, and with the sticky price friction it creates real distortion. However, in a more elaborate DSGE model, better information about future productivity shocks can reduce welfare. Productivity news shocks are of social value in the frictionless economy because the household can make a better capital accumulation decision. Hence, in an economy with many distortions and frictions, it is difficult to judge a priori which shock has direct social value or not.

Angeletos, Iovino, and La'O (2016) use a model with nominal and real rigidities that are based on informational friction to examine the social value of information and 
offer a simple criterion as to which shocks ought to be revealed. They find "[w]hen the business cycle is driven by non-distortionary forces such as technology shocks, welfare unambiguously increases with either private or public information. When instead the business cycle is driven by distortionary forces such as shocks to monopoly markups, welfare unambiguously decreases with either type of information."17 A simple criterion such as this seems unobtainable in the DSGE model we analyzed. Even technology news shocks can have a negative welfare effect; monetary policy news shocks, which are orthogonal to fundamental shocks, can have a positive welfare effect. ${ }^{18}$

Given the difficulty in identifying which shocks are good to reveal, it is a nontrivial task to offer central banks general and simple policy prescriptions for an information strategy about private news, particularly under model uncertainty when realistic frictions and rigidities are possibly present. We therefore conclude that there is no pressing need for Delphic forward guidance according to standard DSGE models. ${ }^{19}$

\section{Conclusion}

When the central bank possesses private information about future economic conditions, should it reveal and/or react to it? In the simple New Keynesian model, a central bank that has a dual-mandate-type objective function finds it optimal to commit to secrecy, by neither revealing nor reacting to private news. In a more elaborate DSGE model with a large number of distortions, frictions, and shocks, conveying private news may improve welfare, but the sign of the welfare effect depends crucially on the shock type, the distortions, and the frictions: the sign of the welfare effect of a news shock can flip when a particular distortion or friction is removed from or added

\footnotetext{
${ }^{17}$ This point is also made in Angeletos and Pavan (2007): "if business cycles are driven primarily by shocks in markups or other distortions that induce a countercyclical efficiency gap, it is possible that providing markets with information that helps predict these shocks may reduce welfare."

${ }^{18}$ Another way to put this is that determining which shocks are distortionary is not at all straightforward.

${ }^{19}$ This result is contrary to the common view which tends to appraise transparency about future shocks. Hirose and Kurozumi (2017) find that anticipated monetary policy disturbances play a larger role in monetary policy transmission mechanism after 1999 and conclude that this is "consistent with the rise in the academic views on central banking as management of expectations."
} 
to the model. According to standard DSGE models, therefore, improving welfare through Delphic forward guidance is difficult, particularly under model uncertainty.

There are mechanisms that are absent in the models in this paper but are likely to counteract the negative effects of information revelation. For example, when the representative household is not an expected utility maximizer but instead has a preference for early resolution of uncertainty, then there can be a direct, positive effect on social welfare from revealing information regarding future shocks to the household. If price setters receive idiosyncratic, noisy private signals regarding future shocks, then the resulting price distribution can be more dispersed than it would be when they have homogeneous information. Providing a public signal may improve welfare by reducing the dispersion of inflation expectations and, hence, that of the price dispersion as in Hellwig (2005), which is the source of inefficiency in the New Keynesian model. It would be interesting to examine whether these mechanisms can more than offset the negative welfare effect found in the present paper, for a set of reasonable parameter values. It is also interesting to examine the optimal time-consistent communication policy in the present setting. These questions are left for our future research.

In an accompanying paper (Fujiwara and Waki, forthcoming), we investigate whether Delphic forward guidance can be useful for the conduct of fiscal policy, using a model without nominal rigidities. We show that it can be harmful for ex ante welfare to convey more accurate information about future policy shocks.

\section{References}

AdAM, K., AND R. M. Billi (2006): “Optimal Monetary Policy under Commitment with a Zero Bound on Nominal Interest Rates," Journal of Money, Credit and Banking, 38(7), 1877-1905.

Angeletos, G.-M., L. IOvinO, And J. LA’O (2016): “Real Rigidity, Nominal Rigidity, and the Social Value of Information," American Economic Review, 106(1), 200-227.

Angeletos, G.-M., AND A. Pavan (2007): “Efficient Use of Information and Social Value of Information," Econometrica, 75(4), 1103-1142. 
Athey, S., A. Atkeson, And P. J. Kehoe (2005): “The Optimal Degree of Discretion in Monetary Policy," Econometrica, 73(5), 1431-1475.

Bassetto, M. (forthcoming): “Forward Guidance: Communication, Commitment, or Both?," Journal of Monetary Economics.

Beaudry, P., And F. Portier (2006): “Stock Prices, News, and Economic Fluctuations," American Economic Review, 96(4), 1293-1307.

(2014): “News-Driven Business Cycles: Insights and Challenges," Journal of Economic Literature, 52(4), 993-1074.

BiAnCHI, F., AND L. Melosi (2018): "Constrained Discretion and Central Bank Transparency," The Review of Economics and Statistics, 100(1), 187-202.

Campbell, J. R., C. L. Evans, J. D. Fisher, And A. Justiniano (2012): “Macroeconomic Effects of Federal Reserve Forward Guidance," Brookings Papers on Economic Activity, 44(1 (Spring), 1-80.

Christiano, L. J., M. Eichenbaum, and C. L. Evans (2005): “Nominal Rigidities and the Dynamic Effects of a Shock to Monetary Policy," Journal of Political Economy, 113(1), 1-45.

CRAWFORD, V. P., AND J. SOBEL (1982): “Strategic Information Transmission,” Econometrica, 50(6), 1431-51.

Cukierman, A., And A. H. Meltzer (1986): “A Theory of Ambiguity, Credibility, and Inflation under Discretion and Asymmetric Information," Econometrica, 54(5), 1099-1128.

Del Negro, M., M. Giannoni, And C. Patterson (2012): “The forward guidance puzzle," Staff Reports 574, Federal Reserve Bank of New York.

EdGE, R. M. (2003): “A Utility-Based Welfare Criterion in a Model with Endogenous Capital Accumulation," Finance and Economics Discussion Series 2003-66, Board of Governors of the Federal Reserve System (U.S.). 
EgGertsson, G. B., And M. WoOdford (2003): “The Zero Bound on Interest Rates and Optimal Monetary Policy," Brookings Papers on Economic Activity, 34(2003-1), 139-235.

FARHI, E., AND I. WERNING (2017): "Monetary Policy, Bounded Rationality, and Incomplete Markets," NBER Working Papers 23281, National Bureau of Economic Research, Inc.

FujiwarA, I. (2005): "Is the Central Bank's Publication of Economic Forecasts Influential?," Economics Letters, 89(3), 255-261.

FujiwarA, I., Y. Hirose, And M. Shintani (2011): “Can News Be a Major Source of Aggregate Fluctuations? A Bayesian DSGE Approach," Journal of Money, Credit and Banking, 43(1), 1-29.

FUJIWARA, I., AND Y. WAKI (forthcoming): "Fiscal forward guidance: A Case for Selective Transparency," Journal of Monetary Economics.

Gabaix, X. (2016): “A Behavioral New Keynesian Model," NBER Working Papers 22954, National Bureau of Economic Research, Inc.

Gaballo, G. (2016): "Rational Inattention to News: The Perils of Forward Guidance," American Economic Journal: Macroeconomics, 8(1), 42-97.

Galí, J. (2008): Monetary Policy, Inflation, and the Business Cycle: An Introduction to the New Keynesian Framework. Princeton University Press, Princeton.

HellwiG, C. (2005): "Heterogeneous information and the welfare effects of public information disclosures," Discussion paper, UCLA.

Hirose, Y., And T. Kurozumi (2017): “Changes in the Federal Reserve Communication Strategy: A Structural Investigation," Journal of Money, Credit and Banking, 49(1), 171-185.

Hirshleifer, J. (1971): "The Private and Social Value of Information and the Reward to Inventive Activity," American Economic Review, 61(4), 561-574. 
Jaimovich, N., And S. Rebelo (2009): “Can News about the Future Drive the Business Cycle?," American Economic Review, 99(4), 1097-1118.

JeHIEL, P. (2015): "On Transparency in Organizations," Review of Economic Studies, 82(2), 736-761.

Jensen, H. (2002): “ Optimal Degrees of Transparency in Monetary Policymaking," Scandinavian Journal of Economics, 104(3), 399-422.

KamenicA, E., And M. GentzKow (2011): "Bayesian Persuasion," American Economic Review, 101(6), 2590-2615.

Lorenzoni, G. (2010): “Optimal Monetary Policy with Uncertain Fundamentals and Dispersed Information," Review of Economic Studies, 77(1), 305-338.

McKay, A., E. NAKAmura, And J. Steinsson (2016): “The Power of Forward Guidance Revisited," American Economic Review, 106(10), 3133-3158.

(2017): “The Discounted Euler Equation: A Note," Economica, 84(336), 820831.

Melosi, L. (2017): "Signalling Effects of Monetary Policy," Review of Economic Studies, $84(2), 853-884$.

MORRIS, S., AND H. S. SHIN (2002): "Social Value of Public Information," American Economic Review, 92(5), 1521-1534.

Moscarini, G. (2007): “Competence Implies Credibility," American Economic Review, 97(1), 37-63.

RAyO, L., AND I. SEgAL (2010): “Optimal Information Disclosure,” Journal of Political Economy, 118(5), 949-987.

Romer, D. H., And C. D. Romer (2000): "Federal Reserve Information and the Behavior of Interest Rates," American Economic Review, 90(3), 429-457.

Schmitt-Grohé, S., AND M. Uribe (2012): “What's News in Business Cycles," Econometrica, 80(6), 2733-2764. 
Smets, F., And R. Wouters (2003): "An Estimated Dynamic Stochastic General Equilibrium Model of the Euro Area," Journal of the European Economic Association, 1(5), 1123-1175.

Smets, F., AND R. Wouters (2007): "Shocks and Frictions in US Business Cycles: A Bayesian DSGE Approach," American Economic Review, 97(3), 586-606.

Stein, J. C. (1989): “Cheap Talk and the Fed: A Theory of Imprecise Policy Announcements," American Economic Review, 79(1), 32-42.

SvENSSON, L. E. (2014): “Forward Guidance," NBER Working Papers 20796, National Bureau of Economic Research, Inc.

Svensson, L. E. O. (2006): "Social Value of Public Information: Comment: Morris and Shin (2002) Is Actually Pro-Transparency, Not Con," American Economic Review, 96(1), $448-452$.

TAKamura, T., T. WAtanabe, And T. Kudo (2006): “Optimal Monetary Policy at the Zero Interest Rate Bound: The Case of Endogenous Capital Formation," Discussion paper, Research Center for Price Dynamics, Institute of Economic Research, Hitotsubashi University.

WAKI, Y., R. DENNIS, AND I. FUJIWARA (2018): “The optimal degree of monetarydiscretion in a New Keynesian model with private information," Theoretical Economics, 13(3), 1319-1367.

WALSH, C. E. (2007): “Optimal Economic Transparency,” International Journal of Central Banking, 3(1), 5-36.

_ (2010): Monetary Theory and Policy. The MIT Press, Cambridge, 3 edn.

Wohltmann, H.-W., And R. C. Winkler (2008): “On the Non-Optimality of Information: An Analysis of the Welfare Effects of Anticipated Shocks in the New Keynesian Model," Economics Working Papers 2008,21, Christian-Albrechts-University of Kiel, Department of Economics. 
Woodford, M. (2003): Interest and Prices: Foundations of a Theory of Monetary Policy. Princeton University Press, Princeton.

(2005): "Firm-Specific Capital and the New Keynesian Phillips Curve," International Journal of Central Banking, 1(2), 1-46. 